\title{
EL DERECHO-DEBER DE PROTECCIÓN DEL MEDIO AMBIENTE
}

NICOLÁS PÉREZ SOLA 
SUMARIO

I. INTRODUCCIÓN. II. EL DERECHO DE DISFRUTE DEL MEDIO AMBIENTE. III. EL DEBER DE PROTECCIÓN DEL MEDIO AMBIENTE. IV. EL ESTADO DE LA CUESTIÓN. 


\title{
EL DERECHO-DEBER DE PROTECCIÓN DEL MEDIO AMBIENTE
}

\author{
NICOLÁS PÉREZ SOLA* \\ Universidad de Jaén
}

\section{INTRODUCCIÓN}

Próximos al cuarenta aniversario de la Constitución española nos parece pertinente llevar a cabo una breve reflexión en torno a la virtualidad del artículo $45 \mathrm{CE}$, al objeto de sistematizar aquellas cuestiones que han constituido el análisis de la doctrina sobre el denominado derecho al medio ambiente, así como respecto de su desarrollo legislativo y su tratamiento jurisprudencial, hasta concluir con el estado de la cuestión en el momento presente.

Hemos pues de comenzar por recordar como la incorporación de la protección ambiental a nuestro ordenamiento jurídico se produce, salvando algunos antecedentes legislativos de diverso alcance, con la constitucionalización del derecho de todos a disfrutar un medio ambiente adecuado. El constituyente se alineaba de este modo con las Constituciones de Grecia (art. 24.1) y Portugal (art. 66.1), aprobadas en los años setenta del pasado siglo, en la incorporación del medio ambiente a la Norma Fundamental. Si bien es cierto que en otros Estados cercanos la relevancia de este derecho se ha producido al margen de una constitucionalización expresa o cuando ésta se ha llevado a cabo no ha dado lugar a su reconocimiento como derecho fundamen-

* Departamento de Derecho Público. Universidad de Jaén. Campus Las Lagunillas s/n. Edificio Ciencias Sociales y Jurídicas (D3).23071 Jaén. Email: nperez@ujaen.es 
tal $^{1}$. El primer caso es el que se aprecia en el estudio de la Constitución italiana, pues a partir del mandato constitucional de tutela del paisaje y de la salud $^{2}$, se ha desarrollado una jurisprudencia en la que se ha afirmado el ambiente como «bien unitario»y «valor primario y absoluto» ${ }^{3}$. Un supuesto diferente es el que ha supuesto la reforma de la Ley Fundamental de Bonn que si inicialmente solo contemplaba esta materia a los efectos de reparto competencial como materia concurrente (art. 72), con la reforma operada en 1994 se ha incorporado la cuestión ambiental desde una perspectiva programática ${ }^{4}$. Se ha producido en fechas más recientes la incorporación de la Charte de environnement ${ }^{5}$ a la Constitución francesa, si bien es cierto que tampoco cabe deducir un reconocimiento expreso de derecho subjetivo alguno al ambiente

1 Para una visión en el derecho comparado entre otros, Understanding Environmental Administration and Law, BuCK, S. J., Island Press, 1996; Law in Environmental Decision-making, JewELL, T., Steele, J., Claredon press Oxford 1998; Ruiz-Rico Ruiz, G., (coord.), Derecho comparado del medio ambiente y de los espacios naturales protegidos, Ecorama, Granda 2000. VERnET, J., JARIA, J., «El derecho a un medio ambiente sano: su reconocimiento en el constitucionalismo comparado y en el derecho internacional», Teoría y Realidad Constitucional, núm. 20, 2007.

2 En este sentido: «La República promueve el desarrollo de la cultura y la investigación científica y técnica. Tutela el paisaje y el patrimonio histórico y artístico de la nación» (art. 9), así como «La República tutela la salud como fundamental derecho del individuo e interés de la colectividad» (art. 32.1). La doctrina italiana se ha mostrado favorable a abordar esta cuestión desde la perspectiva de la Tutela del Ambiente. Ferrara R., Fracchia F. y Olivettit Rason, N., Diritto dell'ambiente, Editori Laterza, 1999; Mazzitelli, A., La tutela dell'Ambiente nella Costituzione, Periferia, Cosenza 1999. Mezzettr, L, (a cura di) Manuale di Diritto Ambientale, Cedam, Padova 2001. Pastore, F., (a cura di) La Tutela dell'ambiente. Un aproccio multidisciplinare, Carocci editore, Roma 2015.

3 Sentencia de la Corte Constitucional italiana, núm. 641 de 1987.

4 «El Estado protege también, teniendo en cuenta la responsabilidad por las generaciones futuras los fundamentos naturales de la vida en el ámbito del orden constitucional, a través de la legislación y, de acuerdo con las medidas de la Ley y el Derecho, a través del poder ejecutivo y de la jurisprudencia» (art. 20 a). En este sentido MEZZETTI, L, «Urbanistica, ambiente e paesaggio nell'ordinamento federale tedesco», en Paesaggio Urbano (dossier di cultura e progetto della cità). Suplemento 3-4, 1998. Op. cit. p. 20.

5 Entre otros contenidos que se incorporan a la Constitución francesa por ley constitucional de 1 de marzo de 2005 se incluye que «Toda persona tiene el derecho de vivir en un ambiente equilibrado y respetuoso con la salud» (art. 1), «el deber de tomar parte en la preservación y mejora del medio ambiente» (art. 2) y »debe, en las condiciones definidas por la Ley, prevenir los perjuicios que provoque en el medio ambiente o, en su defecto, delimitar sus consecuencias». Mathieu, B. «La Constitution et l'environnement. Observations sur la portée normative de la Charte de l'environnement», Cahiers du Conseil Constitutionnel, núm. 15, 2003; Capitani, A., «La Charte constitutionnelle de l'eenvironnement», Revue Française de Droit Costitutionnnel, núm. 63, 2005; Aberasturi Gorriño, U., La Carta del medio ambiente y su valor jurídico como norma de rango constitucional, IeZ: Ingurugiroa eta zuzenbidea -Ambiente y Derecho, n. ${ }^{\circ}$ 7, 2009. 
a tenor de los sucesivos pronunciamientos del Consejo de Estado Francés ${ }^{6}$. En todo caso, si resulta indiscutible que el medio ambiente ha operado una formalización en los tratados internacionales y en la normativa de la Unión Europea $^{7}$.

Ahora bien, el estudio de su configuración constitucional no es a priori una tarea sencilla. La concreción de su alcance y contenido, así como su exigibilidad a efectos de eficacia real de su reconocimiento constitucional, será el objeto de este análisis. Como señalara de forma temprana López Ramón «no es posible definir anticipadamente qué sea el medio ambiente adecuado, porque se trata de un concepto jurídico indeterminado, apropiado para desenvolverse en su concreta aplicación» ${ }^{8}$.

En la medida en que pueda ayudar a delimitar el objeto de estudio, interesa acentuar como para nuestro Alto Tribunal estamos en presencia de un «concepto jurídico indeterminado con un alcance pluridimensional», al que no se puede negar sin embargo su marcado carácter «antropocéntrico y relativo» ${ }^{9}$, por la imposibilidad de formularlo con pretensiones de intemporalidad, más allá de su concreción «en el medio ambiente circundante» ${ }^{10}$. No obstante cabe significar la escasa jurisprudencia constitucional en la materia, ya que las más de las veces tan sólo ha avanzado el TC en la determinación competencial en materia ambiental y competencias transversales en concurrencia con ésta, como ha sucedido con la titularidad para legislar y gestionar espacios protegidos, aguas o recursos naturales y sus efectos en la ordenación general de la economía, a tenor de lo preceptuado en el artículo 149.1.23 CE. En este sentido, podemos señalar las recientes sentencias sobre almacenaje geológico de $\mathrm{CO}_{2}$ (STC 165/2016), eva-

${ }^{6}$ El Consejo Constitucional francés ya había indicado respecto de los artículos 1 y 2 de la Carta que existe una obligación de vigilancia ambiental que se impone a las personas y a los poderes públicos con ocasión de la Decisión n. ${ }^{\circ} 116$ de 8 de abril de 2011, pero con mayor concreción y respecto del preámbulo de la misma y los siete principios que allí se enuncian ha indicado que «considerant que, se ces ont valeur constitucionnnelle, mais qu'aucun d'eux n'institue un droti ou une liberté que la Constitucion garantit» Decisión del Consejo Constitucional n. ${ }^{\circ}$ 394, de 7 de mayo de 2014.

7 Juste Ruiz, J, Derecho Internacional del Medio Ambiente, McGraw-Hill, Madrid, 1999, también I «nuovi diritti» nello stato sociale in trasformazione I. La tutela dell'ambiente tra diritto interno e diritto comunitario, Ferrara, R. Vipiana, P. M., Cedam, 2002.

8 López Ramón, F., «Derechos fundamentales, subjetivos y colectivos al medio ambiente», Revista Española de Derecho Administrativo, núm. 95. Op. cit., p. 359.

9 Para nuestro Alto Tribunal «el carácter complejo y polifacético que tiene las cuestiones relativas al medio ambiente determina precisamente que afecte a los más variados sectores del ordenamiento jurídico» (STC 102/1995).

10 STC 119/2001. 
luación del potencial del uso de la cogeneración en auditorías energéticas (STC 171/2016) o la fracturación hidrológica ${ }^{11}$.

\section{EL DERECHO DE DISFRUTE DEL MEDIO AMBIENTE}

La lectura de los tres apartados del artículo 45 CE suscita algunos interrogantes que abordaremos a continuación. Por otra parte, la ubicación de este precepto en el Capítulo III del Título I de nuestra Carta Magna, pese a su tratamiento prolijo en la doctrina, no ha conseguido una consideración unánime sobre su naturaleza jurídica y eficacia normativa.

En lo que no parece haber duda es en la doble formulación que se contiene en el artículo 45.1 CE que, si de un lado afirma el derecho a disfrutar y, por tanto, la necesidad de proteger y garantizar el ejercicio del mismo, parece tornarse después en un deber colectivo de protección.

La utilización racional de los recursos se convierte en el elemento central del segundo apartado del artículo $45 \mathrm{CE}$. Es cierto que el mandato del constituyente se ha centrado en la imprescindible ponderación entre el desarrollo económico y la protección del ambiente, como garantes ambos de la calidad de vida propugnada en nuestra Norma Fundamental. De un lado, estamos ante un mandato preventivo, que obliga a la racionalidad del uso de los recursos limitados, de la que pueden derivarse restricciones en el ejercicio de derechos subjetivos para salvaguardar los de la colectividad. De otro lado, este derecho-deber constituye el título habilitante para la acción de los poderes públicos para la consecución de objetivos generales del Estado. Por tanto, la proclamación constitucional del derecho al disfrute del medio ambiente puede entrar en conflicto con otros derechos constitucionalizados y reconocidos a los ciudadanos (propiedad privada, libertad de empresa), que conllevarán en ocasiones concretas limitaciones al ejercicio de los mismos, a través de mecanismos como la declaración de utilidad pública o de interés social de bienes y derechos que puedan resultar afectados por la tutela ambiental. El reconocimiento constitucional de la protección del medio ambiente no permite pues afirmar con carácter absoluto su prioridad en detrimento de otros principios e intereses generales a los que además se

11 No cabe ampararse en las competencias estatutarias sobre ordenación del territorio y medio ambiente sino que deben prevalecer las normas del Estado en ejercicio de sus competencias exclusivas en materia de régimen minero y energético y de ordenación general de la economía (SSTC 106, 134 y 208/2014 y 73/2016). 
ha de añadir una elevada dosis de incerteza respecto de las repercusiones de las decisiones y acciones sobre el medio ambiente ${ }^{12}$.

Además, el ordenamiento ambiental dispone de un abanico de instrumentos sancionatorios frente a conductas que entrañan riesgo o causan perjuicios al ambiente. Por consiguiente, si el perjuicio se produce, los poderes públicos han de impulsar una tarea restauradora en la medida en que ésta resulte factible y, evidentemente, una función represora que se contiene en el tercer apartado de este precepto. Como es notorio el derecho penal, en virtud del principio de intervención mínima, actúa de forma accesoria y subsidiaria del derecho administrativo, por ello frente a la infracción de normas administrativas, la sanción penal supone una respuesta a atentados al medio ambiente de «cierta gravedad» ${ }^{13}$.

En cuanto a la constitucionalización de este derecho hemos de recordar el carácter de norma suprema del ordenamiento jurídico de la Constitución, que vincula a los poderes públicos y a los ciudadanos. Pero de la inclusión en el Capítulo III del Título I de nuestra Norma Fundamental del derecho a disfrutar y el deber de conservar un medio ambiente adecuado para el desarrollo de la persona, se derivan algunas consecuencias de extremo interés para su correcta caracterización.

La imposibilidad de otorgar la consideración de derecho fundamental del derecho de disfrute al medio ambiente adecuado ha contado con diversas afirmaciones de nuestro Alto Tribunal al respecto. Así se ha señalado con claridad meridiana que «Derechos fundamentales son, estrictamente, aquellos que, en garantía de la libertad y de la igualdad, vinculan a todos los legisladores, esto es, a las Cortes Generales y a las Asambleas legislativas de las Comunidades Autónomas, sin excepción. Esta función limitativa sólo puede realizarse desde la norma común y superior a todos los legisladores, es decir, desde la Constitución, norma suprema que hace de los derechos que en ella se reconocen un límite insuperable para todos los poderes constituidos y dotado de un contenido que se les opone por igual y con el mismo alcance sustantivo en virtud de la unidad de las jurisdicciones (ordinaria y constitucional) competentes para su definición y garantía. Derechos por tanto, que no se reconocen en la Constitución por ser fundamentales, sino que son tales, justamente por venir proclamados en la nor-

12 «El verdadero e ingente reto para el Derecho en estas situaciones tan frecuentes en materia ambiental es el de la adopción de decisiones en un entorno con frecuencia incierto». EsTeve PARDO, J., «La intervención administrativa en situaciones de incertidumbre científica. El principio de precaución en materia ambiental», en Derecho del Medio Ambiente y Administración Local, Fundación Democracia y Gobierno Local. Op. cit., p. 201.

13 STS de 11 de marzo de 1992. 
ma que es expresión de la voluntad constituyente» ${ }^{14}$. Incluso el TC en su jurisprudencia, pese a que admite la importancia del derecho al medio ambiente de conformidad con el TEDH, ha señalado expresamente que «no puede ignorarse que el artículo $45 \mathrm{CE}$ enuncia un principio rector, no un derecho fundamental». Por tanto corresponde a los Tribunales el deber de «velar por el respeto al medio ambiente, sin duda, pero de acuerdo con lo que dispongan las leyes que desarrollen el precepto constitucional» ${ }^{15}$.

En segundo lugar, no cabe duda que el derecho a disfrutar del medio ambiente ha de informar al legislador positivo, a los órganos jurisdiccionales, así como a los poderes públicos, si bien «sólo podrá ser alegado» de conformidad con lo previsto en las leyes.

En tercer término, debe tenerse en cuenta que este derecho no es susceptible de amparo constitucional. Antes al contrario, inicialmente el derecho a disfrutar el medio ambiente carece de eficacia directa para el ciudadano de la que se derive un derecho subjetivo, sino que precisa de la interpositio legislatoris para su invocación.

Ahora bien, ante la imposibilidad de configurar en nuestro ordenamiento jurídico un derecho al medio ambiente como derecho fundamental, nada impide explorar las posibles vías para alcanzar su tutela judicial ${ }^{16}$. En este sentido, es fácil apreciar la distinción entre la exigencia a los poderes públicos que «velaran» por la protección ambiental y los principios del Capítulo III del Título I de la Constitución que «informarán» la actuación de los poderes públicos, de donde cabe claramente deducir la disponibilidad del recurso ante los órganos jurisdiccionales frente a hipotéticas vulneraciones del derecho a disfrutar de un medio ambiente adecuado ${ }^{17}$. La fundamentación de la protección en materia ambiental

14 «Ya en la propia Constitución bajo el término "derecho” se comprenden tanto verdaderos derechos subjetivos como cláusulas de legitimación para el desarrollo de determinadas opciones legislativas, si bien en ambos casos se trata siempre, al cabo, de mandatos dirigidos al legislador, bien imponiéndole un hacer o una omisión que se erigen en objeto de una pretensión subjetiva exigible ante los Tribunales de justicia; bien obligándole a la persecución de un resultado sin prescribirle específicamente los medios para alcanzarlos y sin hacer de esa obligación el contenido de ningún derechos subjetivo, que sólo nacerá, en su caso, de las normas dictadas para cumplir con ella» (STC 31/2010).

15 STC 199/1996.

16 Puesto que se trata de un derecho difuso a ejercitar por colectivos sociales inicialmente indeterminados «el problema de su articulación jurídica radica en la configuración de procedimientos que permitan una defensa directa ante los órganos jurisdiccionales». RuIz-Rico RuIz, G., El derecho constitucional al medio ambiente, Tirant monografías, Valencia 2000. Op. cit., p. 88.

${ }_{17}$ Frente a otras consideraciones respecto del artículo $53.3 \mathrm{CE}$, se ha señalado que no ha de prevalecer su interpretación desfavorable respecto del artículo $45 \mathrm{CE}$ «Primero, porque supone 
se encuentra inicialmente en el derecho a la tutela judicial efectiva (art. $24 \mathrm{CE}$ ), así como en el mandato a los jueces y tribunales de proteger los derechos e intereses legítimos (arts. 7.3 y 19.1 LOPJ), como a través de la acción popular en los casos y formas previstos en las leyes ante la jurisdicción contencioso-administrativa (art. 19 LJCA).

Aunque durante años se ha analizado en la doctrina la naturaleza jurídica de este mandato constitucional, hoy parece superado, al menos a efectos meramente nominativos, este debate ${ }^{18}$. Por cuanto respecta a las notas identificativas del mismo, se ha afirmado con insistencia su carácter prestacional ${ }^{19}$, reaccional, de inequívoca satisfacción con la intervención administrativa ${ }^{20}$ y que admite su disfrute también de modo colectivo ${ }^{21}$ y es susceptible de posesión ${ }^{22}$. El ejercicio de este derecho no se debe plantear exclusivamente como una exigencia ante las Administraciones, ni se agota con la adopción de políticas públicas ambientales

entender que las garantías establecidas para los diversos derechos y principios enunciados en el título I de la Constitución se limitan al cuadro del artículo 53 de la Constitución. Segundo, porque ignora que el artículo 53.3 de la Constitución únicamente se refiere a los "principios reconocidos en el capítulo III", sin comprender por tanto a los derechos reconocidos en el mismo lugar. Tercero, porque contradice el contenido del derecho fundamental a la tutela judicial efectiva de "derechos e intereses legítimos" (art. 24.1 de la Constitución), en la medida en que niega la tutela judicial de un derecho recogido en el propio texto fundamental». López Ramón, F., «Derechos fundamentales, subjetivos y colectivos al medio ambiente», Revista Española de Derecho Administrativo, núm. 95. Op. cit., p. 347 y ss.

18 Respecto de las consecuencias de su ubicación constitucional sí parece claro que «en todo caso, la indeterminación del objeto plantea dudas sobre cuál sea el medio ambiente adecuado para el desarrollo de la persona». López RAmón, F., «Derechos fundamentales, subjetivos y colectivos del medio ambiente», Revista Española de Derecho Administrativo, núm. 95, op. cit., p. 358.

19 Requiere la intervención de los poderes públicos para preservar o prevenir los daños al equilibrio ecológico, conexo a la calidad de vida humana, que garantiza nuestra existencia y la de las generaciones venideras. En este sentido, EscobAr RocA, G., La ordenación constitucional del medio ambiente FIDA Dykinsons, Madrid 1995. Op., cit., pp. 82-83.

20 Pero como señalara Alexy «todo derecho a una acción positiva, es decir, a una acción del Estado, es un derecho prestacional. De esta manera el derecho prestacional es la contrapartida exacta del concepto de un derecho de defensa» por lo que con frecuencia se ha clasificado como «derecho social fundamental». Alexy, R., Teoría de los Derechos Fundamentales, Centro de Estudios Políticos y Constitucionales, Madrid, 2007. Op. cit., pp. 391-392.

21 Así para Martín Mateo los derechos subjetivos «son derechos de cuño individualista y antrópico, mientras que el derecho ambiental tiene un substratum intrínsecamente colectivo y naturista que pretende proteger al hombre desde luego, pero también al medio terráqueo en cuanto tal». Martín Mateo, R., Tratado de Derecho Ambiental, vol. I. Trivium, Madrid, 1991. Op. cit., p. 45.

22 «El derecho subjetivo al medio ambiente es un derecho de disfrute (...) y es plural y por lo tanto susceptible de posesión», Jordano FragA, J., La protección del derecho a un medio ambiente adecuado, Bosch editor, Barcelona, 1995. Op. cit., p. 500. 
o resoluciones administrativas sancionadoras o jurisdiccionales de condena, sino que el uso y disfrute de los bienes ambientales es el núcleo esencial del derecho ${ }^{23}$.

En efecto, se ha pretendido responder a la cuestión fundamental de si el ciudadano es sujeto de un derecho subjetivo con fundamento en su reconocimiento constitucional y, por tanto, en qué posición se sitúa el ciudadano ante la positivación de este derecho ${ }^{24}$ en el contexto de los principios rectores de la política social y económica. Si bien es cierto que durante mucho tiempo se ha observado el Capítulo III del Título I como una foto fija, consideramos más apropiada en el momento actual «la perspectiva de la dinámica constitucional, la línea de separación que distancia a los principios rectores de los genuinos derechos fundamentales se hace bastante más tenue» ${ }^{25}$. Por ello, se ha afirmado que estamos en presencia de un derecho subjetivo ${ }^{26}$, de diversa caracterización. Así se ha destacado su naturaleza constitucional y su configuración legal que posibilita la protección judicial ordinaria ${ }^{27}$. También se ha resaltado el carácter de «derecho subjetivo mediato» ${ }^{28}$. Ciertamente los ciudadanos afectados pueden

${ }^{23}$ Compartimos con Loperena que «el derecho de cada ciudadano sobre el medio ambiente no se proyecta sobre la Administración exclusivamente, en una relación bilateral. El derecho al medio ambiente adecuado es un derecho que se ejerce frente a todos, que se ejerce por cada uno frente a todas las personas físicas o jurídicas e instituciones». LOPERENA ROTA, D., Los principios del derecho ambiental, Civitas, Madrid 1998. Op. cit., p. 76 y ss.

24 Por lo que añade Delgado Piqueras «El deber del legislador no consiste en redundar una proclamación general que ya sanciona la Constitución ni tampoco establecer una definición universalmente válida del derecho (...) sino en extender y hacer realidad su verificación en los distintos sectores del ordenamiento que le afectan». Delgado Piqueras, F., «Régimen jurídico del derecho constitucional al medio ambiente», Revista Española de Derecho Constitucional, núm. 38, 1993. Op. cit., pp. 54-55.

25 En este sentido Cascajo Castro, J. L., «Derechos Sociales», en Derechos Sociales y Principios Rectores, Actas del IX Congreso de la Asociación de Constitucionalistas de España, CasCajo CAStro, J. L., Terol Becerra, M., Domínguez Vila, A., Navarro Marchante, V. (Coords.) Valencia, 2012, Tirant lo Blanch. Op. cit., p. 25.

26 «Derecho (público subjetivo) al libre desarrollo de la persona en un entorno (medio ambiente) adecuado». Velasco Caballero, F., «Comentario al Artículo 45» en Comentarios a la Constitución Española, XXX aniversario Wolters Kluwer, CASAS BAAMONDE, M. E., y RodríGUEZPiñero y Bravo-Ferrer, M., Madrid, 2008. Op. cit., p. 1091.

27 Delgado Piqueras, F., «Régimen jurídico del derecho constitucional al medio ambiente», Revista Española de Derecho Constitucional, núm. 38, 1993. Op. cit., p. 56.

28 «Por un lado, como "posición jurídica garantizada” o como "interés jurídicamente protegido" se ha colocado la relación de disfrute sobre un bien jurídico colectivo. De otro, se ha otorgado "una facultad de poder exigir del Estado u otro órgano de la administración una acción y omisión concretas correspondientes a esta posición”, o "un apoderamiento para la actuación en su defensa”, pues el artículo 53.3 faculta a los titulares para su alegación ante los tribunales ordinarios en la medida en que tal derecho haya sido delimitado por las leyes. Estos dos elementos perfectamente definidos son 
hacer valer su derecho al medio ambiente siguiendo cualquiera de las vías que ofrece la legislación vigente ${ }^{29}$ (art. 53.3 CE).

En resumen, la caracterización como un derecho subjetivo con fundamento en el artículo $45 \mathrm{CE}$ ha tenido acogida en la doctrina con diversa intensidad ${ }^{30}$ dada la débil protección del mismo ${ }^{31}$, a juzgar por su ubicación en el Capítulo III, su impreciso contenido, las novedosas formas que plantea su titularidad colectiva o el objeto sobre el que recae: la Naturaleza. También se ha considerado derecho subjetivo pese a las dificultades señaladas poniendo en valor su dimensión procedimental. No obstante resulta evidente que del enunciado del artículo 45 CE no se deduce un contenido esencial ni tampoco un reconocimiento jurídico de su invocación ante los tribunales ${ }^{32}$.

Además conviene recordar que no se ha despejado el interrogante sobre en qué consiste el disfrute individual y en su caso colectivo, de un «bien colectivo» como lo es la naturaleza y los recursos naturales y qué se ha de entender por adecuado al desarrollo de las personas ${ }^{33}$.

los componentes de un verdadero derecho subjetivo. La consecuencia es clara, como derecho subjetivo, el derecho al medio ambiente es susceptible de tutela efectiva». JorDANO FrAGA, J., La protección del derecho a un medio ambiente adecuado, Bosch editor, Barcelona, 1995. Op. Cit., p. 483.

29 «Tienen una trascendencia jurídica limitada, no obstante el carácter normativo que se predica in totum de la Constitución ya que precisan de su concreción a través de una Ley sin que en su defecto puedan ser alegados directamente ante los Tribunales, lo que les priva de la cobertura jurídica más efectiva». Martín Mateo, R., Tratado de Derecho Ambiental, Vol I. Trivium, Madrid, 1991. Op. cit., p. 45.

30 Incluso se ha formulado una consideración diferenciada según la que el artículo 45.1 CE reconoce el derecho al medio ambiente adecuado mientras que los restantes apartados de este precepto reconocen un «derecho a la protección del medio ambiente adecuado» que si resultaría ejercitable frente al Estado. Loperena Rota, D., Los principios del derecho ambiental, Civitas, Madrid, 1998. Op. cit., p. 54.

31 «Adquiere el perfil de un verdadero derecho subjetivo, que inicialmente no tiene, por intermedio del legislador ordinario, que está obligado a concretar los precisos contornos que haya de tener en cada caso». Fernández, T. R., 1981. Op. cit., p. 346.

32 «Las técnicas de positivación de los derechos fundamentales requieren que éstos se refieran a situaciones bien determinadas en cuando a su objeto y titularidad. Ahora bien, resulta difícil establecer con precisión el conjunto de facultades constitutivas del derecho al medio ambiente» para añadir a continuación «Es sabido que los derechos fundamentales constituyen estructuras inmediatamente conexas con los valores de una sociedad considera básicos para su colectividad. Ahora bien, la noción de ambiente o la de medio ambiente no tiene de por sí una significación prescriptiva sino descriptiva». PÉrez LuÑo, A. E., «Artículo 45. Medio Ambiente», en AlZaga VillaAmil, O., (dir.) Comentarios a las leyes políticas, ED RDP, Madrid, vol. IV. Op. cit., p. 262.

33 «La naturaleza colectiva de la naturaleza la hace poco o nada propicia a ser objeto de disfrute, al menos en el sentido técnico-jurídico». BETAncor RodríguEz, A., Derecho Ambiental, La Ley, Madrid, 2014. Op. cit., p. 507. 
Las repercusiones que para el ordenamiento jurídico tiene el reconocimiento constitucional de este derecho se pueden concretar a través del análisis de su desarrollo legislativo como de la interpretación jurisprudencial del mismo, dada la tendencia expansiva que presenta el contenido material del medio ambiente dotado además de gran dinamismo. Ahora bien, el hecho de que el legislador no haya elaborado una norma general sobre la protección constitucional del medio ambiente en desarrollo del artículo $45 \mathrm{CE}$, impide inicialmente una mayor concreción respecto del alcance y contenido de este derecho que lo es de configuración legal, que impone obligaciones individuales de preservar el medio ambiente, pero también impone a los poderes públicos la obligación de legislar para posibilitar el ejercicio de este derecho ${ }^{34} \mathrm{y}$, en su caso, la imposición de sanciones por el incumplimiento del deber de preservación. La cuestión que se sucita es «si los deberes obligan a los particulares y si obligan frente a los particulares» ${ }^{35}$. En efecto, esta ausencia obliga al intérprete a acudir a diversas normas sectoriales para pergeñar el objetivo que el constituyente ha querido introducir en el citado precepto.

Parece necesario esbozar algunos elementos que ayuden a delimitar el contenido de este derecho constitucional que lo es de «disfrute» y los bienes jurídicos a tutelar. En este sentido se ha señalado la posibilidad de reconocer un derecho defensa, un derecho de protección, un derecho de procedimiento e incluso un derecho a una prestación fáctica ${ }^{36}$. Hemos señalado la ausencia de una norma general de desarrollo de este precepto constitucional, ya que tan sólo en determinadas normas sectoriales cabe encontrar un desarrollo explícito del artículo $45 \mathrm{CE}^{37}$. Por esta razón quizá resulte indicado acudir, a efectos instrumentales, al desarrollo legislativo sectorial como al tratamiento jurisprudencial que se ha llevado a cabo del artículo $45 \mathrm{CE}$ si bien, las más de las veces, por imperativo del derecho ambiental de la Unión Europea ${ }^{38}$ y, en menor medida,

34 Pérez Luño habla de función preventiva, función restauradora y función promocional. «Artículo 45. Medio Ambiente», en Alzaga Villaamil, O., (dir.) Comentarios a las leyes políticas, ED RDP, Madrid, Vol. IV, op. cit., p. 267-269.

35 Alegre Martínez, M. A., «Los deberes en la Constitución española: esencialidad y problemática». Teoría y Realidad Constitucional. Op. cit., p. 287.

36 Abramovich, V., Courtis, Ch., Los derechos sociales como derechos exigibles, Trotta, Madrid, 2002. Op. cit., p. 129.

37 Sucedía así en la Ley 22/1988 de Costas en donde se afirmaba que «la utilización del domino público (...) será libre» (art. 31) o en la Ley 4/1989 de Conservación de la naturaleza, la flora y la fauna silvestre que recogía que la gestión de los recursos naturales se llevaría a cabo «con los mayores beneficios para las generaciones actuales» pero con garantía de su conservación «para satisfacer las necesidades y aspiraciones de las generaciones futuras».

38 Krämer, L., Derecho ambiental y Tratado de la Comunidad Europea, Marcial Pons, Barcelona, 1999. 
de la jurisprudencia del TEDH, para clarificar el alcance y el contenido de este derecho. Ciertamente la necesaria trasposición de la legislación de la Unión Europea en materia de medio ambiente ha impedido la inacción u omisión estatal del desarrollo legislativo en materia ambiental ${ }^{39}$.

Así el legislador ha concretado algunos de los contenidos del artículo 45 CE al señalar como objeto de la Ley 47/2007, del Patrimonio Natural y la Biodiversidad la regulación del régimen jurídico básico de la conservación sostenible, mejora y restauración del patrimonio natural y de la biodiversidad como parte del deber de conservar y el derecho a disfrutar de un medio ambiente adecuado para el desarrollo de la persona (art. 1). En el mismo sentido pero tan solo en la exposición de motivos de la Ley 34/2007, de Calidad del Aire y Protección de la Atmósfera se recoge el derecho de los ciudadanos a «exigir a los poderes públicos que adopten las medidas necesarias para preservar la pureza del aire dentro de unos límites que no comprometan su salud y la protección del medio ambiente», para añadir a continuación, que «en la misma medida se nos debe demandar a todos la obligación de preservar y respetar este recurso natural».

En el ámbito autonómico cabe destacar la Ley 3/1998, General de Protección del Medio Ambiente del País Vasco, con la que el legislador persigue el objeto de determinar los derechos y deberes de las personas físicas y jurídicas en la materia, con un entendimiento del medio ambiente como «bien social generador de derechos y obligaciones individuales y colectivas» (art. 2). La doble perspectiva ya apuntada se recoge al afirmar que el derecho de todas las personas lo es de «uso y disfrute de un medio ambiente saludable» (art. 3.1), para añadir a continuación que la obligación recae sobre las administraciones públicas de «promover políticas ambientalmente adecuadas para garantizar el ejercicio» del mismo.

Por otra parte, en la configuración del derecho de todos a disfrutar de un medio ambiente adecuado hay que reconocer que el desarrollo legislativo interno es deudor del derecho ambiental de la Unión Europea, a partir del cual se ha concretado el alcance y contenido del mismo en numerosos aspectos ${ }^{40}$. Aunque para ello hayan sido precisas numerosas condenas por el TJUE al Estado español por el reiterado incumplimiento de las exigencias ambientales de la Unión Europea.

39 Entre otros, Villaverde MenÉndez, I., La inconstitucionalidad por omisión, McGraw-Hill, Madrid, 1997.

40 Canosa Usera se ha referido al necesario rellenado del artículo $45 \mathrm{CE}$ «al tratarse de un interés social difuso, de perfiles muy lábiles» ante la ausencia de desarrollo concreto del mismo por norma subconstitucional con la consiguiente ruptura de «la necesaria continuidad material del orden jurídico en materia ambiental». CANosa Usera, R., Constitución y Medio Ambiente, Ciudad Argentina Dykinson, 2000. Op. cit., p. 82. 
Las instituciones comunitarias han desarrollado un conjunto normativo ambiental que inicialmente carecía de un claro presupuesto habilitador pero que, respaldado desde la jurisprudencia del Tribunal de Justicia, ha configurado posteriormente un ordenamiento jurídico sectorial orientado a la prevención, conservación y reparación de las agresiones al ambiente incorporando como principios el de precaución así como el de quien contamina paga. Qué duda cabe que a partir de aquél se han incrementado las obligaciones del Estado español, impulsando el ordenamiento comunitario la labor del legislador y la actuación de las administraciones y los tribunales para la mejora de la calidad de vida y la recuperación del medio ambiente, dotando de efectividad el mandato constitucional. En la medida en que una vez incorporado al ordenamiento interno constituye una obligación para los poderes públicos, resulta accionable ante los tribunales en caso de incumplimiento por aquéllos. Entre los elementos más significativos que han penetrado a través de su transposición ${ }^{41}$, al objeto de dotar de contenido material al derecho de disfrute del medio ambiente, cabe señalar el derecho de acceso a la información ambiental ${ }^{42}$, a la participación en determinados planes y programas ${ }^{43}$ como en el acceso a la justicia, en caso de su incumplimiento ${ }^{44}$.

41 En efecto, la Ley 27/2006 por la que se regulan los derechos de información, participación pública y acceso a la justicia en materia de medio ambiente que transpone al ordenamiento interno las disposiciones comunitarias en la materia.

42 Se han de tener en cuenta las previsiones de la Ley 16/2002 de Prevención y Control integrado de la Contaminación en cuanto otorgan la consideración de información pública a la relativa a las principales emisiones y focos de las mismas así como a los valores límite de emisión autorizados (art.16) y la Ley 37/2003 del Ruido que incluye la obligación de las Administraciones de informar «al público sobre la contaminación acústica y, en particular, sobre los mapas de ruido y los planes de acción en materia de contaminación acústica» (art. 5). También la Ley 42/2007 del Patrimonio Natural y la Biodiversidad recoge «La garantía de la información a la ciudadanía» (art. 3.c). El acceso a la información ambiental en materia de aguas y planes hidrológicos tiene un tratamiento específico, ya que en esta normativa concreta se ha previsto el derecho de acceso a la información sobre éstas y, en particular, la relativa a vertidos y a la calidad de las aguas.

43 La regulación sobre la participación en materia ambiental se completa con la Ley 9/2006 sobre la Evaluación de los efectos de determinados planes y programas en el medio ambiente. En el mismo sentido, la Ley 42/2007 del Patrimonio Natural y la Biodiversidad recoge la participación de la ciudadanía «en el diseño y ejecución de las políticas públicas, incluida la elaboración de disposiciones de carácter general, dirigidas a la consecución de los objetivos de esta ley» (art. 3, c). La legislación de aguas contempla la participación ciudadana en el procedimiento para la elaboración y revisión de los planes hidrológicos de cuenca en los que se debe contemplar, en todo caso, la programación de calendarios, programas de trabajo, elementos a considerar y borradores previos para posibilitar una adecuada información y consulta pública desde el inicio del proceso.

44 De tal modo que el público que considere que un acto, o en su caso, una omisión imputable a una autoridad pública ha vulnerado su derecho en materia de información y participación 
Ahora bien, este reconocimiento de legitimación y acceso a la justicia que se deriva del ordenamiento comunitario contiene la expresa referencia a su conformidad con el derecho interno y, por ello, no resuelve los términos en que debe ser interpretada la capacidad para recurrir a los tribunales de «los miembros del público interesado», lo que exige un considerable análisis jurisprudencial para determinar el alcance real de dicha legitimación. El derecho al medio ambiente introduce, como es notorio, nuevas formas de titularidad, especialmente a los efectos procesales, más allá de la concepción individualizada de la legitimación, que requiere innovadoras respuestas del legislador para la defensa de los denominados intereses difusos. En materia de medio ambiente se pueden producir daños indirectos o potenciales a destinatarios de difícil individualización, a los que sólo en contadas ocasiones se les faculta para instar la defensa de sus intereses. Por tanto, habrá que acudir a la regulación específica para constatar el tratamiento de la legitimación en materia ambiental, en la medida en que tenga cabida no sólo para los ciudadanos, sino también para asociaciones y grupos que resulten afectados, o que estén legalmente habilitados para su defensa y promoción.

En resumen, se trata de materializar a través del desarrollo legislativo expreso los supuestos en los que el ordenamiento «otorga legitimación a cualquier ciudadano sin necesidad de acreditar un derecho o interés legítimo, ya que la legitimación le viene otorgada para la defensa de los intereses colectivos tutelados por la propia norma» ${ }^{45}$. Como ya señaló el Tribunal Supremo «el carácter amplio, difuso y colectivo de los intereses y beneficios que con su protección se reportan a la misma sociedad (...) nos obliga a configurar un ámbito de legitimación en esta materia, en el que las asociaciones debemos considerarlas como investidas de un especial interés legítimo, colectivo, que nos deben conducir a entender que las mismas, con la impugnación de decisiones medioambientales

pública puede interponer los recursos pertinentes. El legislador ha recogido en esta norma la acción popular en asuntos ambientales frente a actos u omisiones imputables a las autoridades públicas que vulneren las normas relacionadas con la participación de los ciudadanos en la elaboración, modificación y revisión de las disposiciones de carácter general que versen sobre las materias que se contienen en el artículo 18 (art. 22). Además, la Ley 26/2007, de Responsabilidad Medioambiental igualmente incorpora el tratamiento de los interesados para poner en marcha el procedimiento de exigencia de responsabilidad medioambiental, dando cabida a «cualquier persona jurídica sin ánimo de lucro» que acredite, en los términos ya comentados, el cumplimiento de los requisitos, pudiendo formular la exigencia de responsabilidad medioambiental a través de escrito y con especificación del daño o amenaza de daño a los recursos naturales protegidos por la ley.

45 Vera Jurado, D. J., «La acción pública en materia de medio ambiente», en Intereses colectivos y legitimación activa, Carbonell Porras, E., (Dir.) y Cabrera Mercado, R., (Coord.) Thomson-Reuters Aranzadi Universidad de Jaén. Op. cit., pp. 380-381. 
no están ejerciendo exclusivamente una defensa de la legalidad vigente, sino que están actuado en defensa de unos intereses colectivos que quedan afectados por el carácter positivo o negativo de la decisión administrativa que impugna» ${ }^{46}$. En todo caso, cabe recordar al respecto que nuestro Alto Tribunal «tiene que guiarse por el principio hermenéutico pro actione, que opera en el ámbito del acceso a la jurisdicción con especial intensidad» ${ }^{47}$. En el caso concreto de ONGs Ambientales es claro su objetivo de defensa de la naturaleza y, por tanto, tienen «un interés legítimo y personal en velar por el correcto ejercicio de la potestad administrativa»(STC 34/1999). Sin embargo, recientemente el Tribunal Supremo ha reiterado en diversas ocasiones que «propiamente no existe una acción pública medioambiental (...) el ordenamiento jurídico no concede una acción pública en materia de protección del medio (....) solo otorga acción popular a las personas jurídicas sin ánimo de lucro y solo cuando cumplen los requisitos de su artículo 23» ${ }^{48}$. Como se constatará más adelante, la intervención procesal de ONGs ambientales ha sido determinante en procedimientos judiciales en los que se ha resuelto incumplimientos de deberes de protección ambiental de los poderes públicos esencialmente a través de la jurisdicción contenciosoadministrativa.

Las dudas ya apuntadas sobre la naturaleza jurídica y eficacia normativa del artículo 45.1 CE, ante la escasa jurisprudencia constitucional en la materia, han encontrado en las sucesivas condenas al Estado español por el TEDH, un interesante argumentario respecto de la invocabilidad ante las administraciones y los órganos jurisdiccionales internos de los elementos configuradores del derecho a disfrutar del medio ambiente. Ahora bien es preciso contextualizar el ámbito en el que el Tribunal de Estrasburgo y el TC pueden establecer una comunicación en orden a la protección ambiental en general y frente a la injerencia que supone la contaminación acústica en particular. Pese a que por el TEDH se ha llevado a cabo una interpretación amplia del contenido de los derechos protegidos por el $\mathrm{CEDH}$, en el marco de nuestra justicia constitucional se hace difícil por el momento algún reconocimiento de un «componente subjetivo» del derecho a un medio ambiente adecuado para el desarrollo de la persona ${ }^{49}$.

Pese a las diferencias presentes en el sistema convencional y en nuestra justicia constitucional, si debemos resaltar la novedosa jurisprudencia que construye el TEDH sobre el artículo $8 \mathrm{CEDH}$, ya que por éste se considera que «la

46 STS de 25 de junio de 2008.

47 STC 188/2003.

48 STS 16 de junio de 2016.

49 Hemos analizado esta cuestión en PÉrez Sola, N., La defensa convencional de los derechos en España. ¿Es posible el diálogo entre tribunales? INAP, Madrid 2015. 
vulneración del derecho al respeto del domicilio no se circunscribe a las vulneraciones concretas o físicas, como la irrupción no autorizada de otra persona en su domicilio, sino que también incluye agresiones inmateriales o incorpóreas, como ruidos, emisiones, olores y otras injerencias». Si las agresiones son graves pueden constituir la violación del derecho de la persona al respeto de su domicilio porque le impiden disfrutar de sus comodidades. En efecto, haciendo acopio de su jurisprudencia se puede seguir paso a paso la construcción de toda una doctrina sobre la repercusión del ruido y la contaminación acústica en la vida privada de las personas que contrasta, sin duda, con el entendimiento del ámbito de protección de la vida privada a la luz de la jurisprudencia del TC.

La argumentación fundamental desarrollada por el Tribunal de Estrasburgo consiste en sostener la interpretación del artículo 8 del CEDH que admitiría su aplicación a los asuntos medioambientales «sea la contaminación directamente causada por el Estado o que la responsabilidad de éste último se desprenda de la ausencia de una normativa adecuada de la actividad del sector privado» ${ }^{50}$. Por tanto, el Tribunal debe corroborar si los daños producidos por el ruido «superaron el umbral mínimo de gravedad para constituir una violación del artículo 8 del $\mathrm{CEDH}$ ». Cuando el Tribunal encuentra «un vínculo de causalidad entre los ruidos y los daños continuados y las afecciones» de un lado y, por las autoridades no se adoptaron las medidas necesarias para proteger el derecho del demandante al respeto de su domicilio, vida privada y familiar, entonces concluirá que ha existido una violación del artículo 8 del CEDH. Con estos antecedentes, el impacto de la sentencia del Tribunal Europeo en el Caso López Ostra ${ }^{51}$ debe ser destacado, en la media en que abrió una línea argumental del mayor interés para dotar de fundamentación la discutida efectividad del mandato constitucional del artículo $45 \mathrm{CE}$. La conexión realizada por el TEDH entre la violación del derecho a la intimidad en el domicilio y el deterioro del medio ambiente en el marco del CEDH constituye, sin duda, un tratamiento novedoso respecto al derecho a la inviolabilidad del domicilio recogido en el artículo 18.2 CE, que deja la puerta abierta a otras posibles conexiones entre otros derechos fundamentales y el derecho de todos a disfrutar de un medio ambiente adecuado.

Pero en la resolución del Caso López Ostra existen otros elementos de interés que refuerzan la consideración del Tribunal de Estrasburgo en orden a afirmar

50 «Una injerencia de las autoridades públicas en el ejercicio del derecho al respeto de la vida privada o del domicilio».

51 El TEDH ha señalado que «los atentados graves al medioambiente pueden afectar al bienestar de una persona y privarla del goce de su domicilio, alterando su vida privada y familiar sin que sea necesario poner en peligro la salud del interesado» (Caso López Ostra contra España, STEDH de 9 de diciembre de 1994). 
la vulneración por el Estado español del CEDH. En efecto, la constatación de que por parte de las autoridades no se adoptaron todas las iniciativas orientadas a superar la situación de molestias de la recurrente y que «los interesados tuvieron que sufrir durante más de tres años las molestias causadas por la planta antes de mudarse, con los inconvenientes que ello supone», nos advierte de una situación prolongada a lo largo de una período de tiempo considerable junto a una inactividad de la administración competente para poner fin a dicha situación. La conclusión que alcanza el TEDH para fundamentar su condena al Estado español es que la autoridad interna «no supo encontrar un justo equilibrio entre el interés del bienestar económico de la ciudad de Lorca — disponer de una planta depuradora- y el efectivo disfrute por parte de la actora del derecho al respeto de su domicilio y de su vida privada familiar».

Por tanto, el interés de esta jurisprudencia recae en su virtualidad a la luz del artículo 10.2 CE para constatar una protección constitucional frente a la contaminación acústica con base en los derechos fundamentales a la intimidad personal y familiar. El TEDH en el Caso Moreno Gómez, por injerencias en la intimidad domiciliaria por contaminación acústica, señala que «no se refiere a una injerencia de las autoridades públicas en el derecho al respeto del domicilio, sino a su incapacidad de actuar para impedir que un tercero vulnere el derecho alegado por la demandante». Surge así un elemento relevante, el valorativo respecto de la entidad o consistencia de la prueba. La novedad en la resolución de este asunto está en el hecho de que el Tribunal de Estrasburgo considera que sería excesivamente formalista exigir tales pruebas en el presente caso, ya que las autoridades municipales han declarado la zona en que reside la demandante «zona acústicamente saturada» ${ }^{52}$. Concluye el Tribunal que el Estado español «no ha sido capaz de cumplir con su obligación positiva de garantizar el derecho de la demandante al respeto de su domicilio y de su vida privada, incumpliendo así el artículo $8 \mathrm{CEDH».}$

Una breve referencia también se hace necesaria al Caso Martínez Martínez ${ }^{53}$. En esta sentencia reitera el TEDH como «el artículo $8 \mathrm{CEDH}$ puede aplicarse en los asuntos medioambientales sea la contaminación directamente causada por el Estado o que la responsabilidad de éste último se desprenda de la ausencia de una normativa adecuada de la actividad del sector privado». Por tanto, corresponde al Tribunal concretar si los daños cuyo origen estaba en el ruido producido superaron el «umbral mínimo de gravedad» para constituir una violación del artículo 8. El resultado de dicha valoración permite apreciar al Tribunal de Estrasburgo, a tenor de «la intensidad de los ruidos padecidos — nocturnos y

52 Caso Moreno Gómez contra España, STEDH de 16 de noviembre de 2004.

53 Caso Martínez Martínez contra España, STEDH de 18 de octubre de 2011. 
superando altamente el nivel permitido- y debido a que estos fueron continuos durante años», un incumplimiento por parte del Estado español de su obligación de garantizar el derecho del demandante al respeto de su domicilio y su vida privada, ignorando el artículo 8 del CEDH.

Es cierto que las resoluciones comentadas del Tribunal de Estrasburgo han conseguido impulsar una aún tímida tentativa de construcción de una incipiente protección del ciudadano frente a los poderes públicos por episodios de contaminación acústica, que han tenido continuidad en sucesivas sentencias condenatorias en vía penal del Tribunal Supremo por contaminación acústica. Pero las aportaciones del TEDH hasta ahora comentadas no suplen ni permiten superar los límites constitucionales impuestos al derecho de todos al medio ambiente, que han quedado sucintamente expuestos con anterioridad; incluso la recepción de esta jurisprudencia formalmente incorporada por nuestro Alto Tribunal, contrasta con la dificultad concreta para asumir las consecuencias que de ella se derivan como se puede constatar en las SSTC 119/2001, 16/2004, 25/2004 y $150 / 2011$.

Inicialmente nuestro Alto Tribunal en la STC 119/2001 mostró una consideración progresiva en el ámbito de la protección de los derechos al admitir que «los derechos a la integridad física y moral, a la intimidad personal y familiar y a la inviolabilidad del domicilio han adquirido también una dimensión positiva en relación con el libre desarrollo de la personalidad, orientada a la plena efectividad de estos derechos fundamentales». En esta resolución se actualiza la doctrina del Tribunal de un lado, pero se atisban también dudas razonables a cerca del alcance del objeto de protección, a través de sendos votos particulares que acompañan el parecer mayoritario del Tribunal.

En primer lugar, y en relación con la hipotética vulneración del derecho a la integridad física y moral (art. $15 \mathrm{CE}$ ), considera el TC que «en determinados casos de especial gravedad, ciertos daños ambientales aun cuando no pongan en peligro la salud de las personas, pueden atentar contra su derecho al respeto de la vida privada y familiar, privándola del disfrute de su domicilio». Si bien matiza nuestro Alto Tribunal que «no todo supuesto de riesgo o daño para la salud» implicaría su conculcación.

En segundo término, admite también el TC la relevancia de la jurisprudencia del Tribunal de Estrasburgo respecto de la contaminación acústica y la lesión del derecho a la intimidad, en la medida en que señala «el valor que por virtud del artículo 10.2 CE ha de reconocerse» a su doctrina «en su interpretación y tutela de los derechos fundamentales» (STC 35/1995). Hemos de destacar además, la autoafirmación del Alto Tribunal respecto de su ámbito competencial y autonomía interpretativa que le lleva a matizar el alcance de este reconocimien- 
to. A partir de aquí el TC impone un criterio propio frente a los precedentes jurisprudenciales antes apuntados, singularmente los que contienen condena al Estado español, afirmando que esta jurisprudencia del TEDH «no supone una traslación mimética del referido pronunciamiento que ignore las diferencias normativas existentes entre nuestra Norma Fundamental y el CEDH, ni la (...) necesidad de acotar el ámbito del recurso de amparo a sus estrictos términos en garantía de la operatividad y eficacia de este medio excepcional de protección de los derechos fundamentales».

Pero al objeto de esta reflexión quizá resulta más relevante la doctrina que se contiene en los dos votos particulares de la citada STC 119/2001. En efecto, en el Voto particular que formuló el Magistrado Jiménez de Parga, se apunta «la conveniencia de hablar de un triple escalón de protección constitucional que, en sentido descendente, iría desde el derecho a la integridad física y moral (art. 15) hasta el derecho al medio ambiente adecuado para el desarrollo de la persona (art. 45.1 CE), pasando por el derecho a la intimidad domiciliaria (art. 18 CE)». Con esta triple dimensión instrumental, considera el Magistrado que se persigue «reivindicar este contenido o componente subjetivo» del derecho a un medio ambiente adecuado para el desarrollo de la persona.

Por otra parte, en el Voto particular formulado por el Magistrado Garrido Falla se plantea desde una perspectiva totalmente diferente una cuestión de la mayor relevancia, esto es «hasta qué punto la administración pública requerida está obligada a dispensar la protección que de ella se solicita». Esta previa obligación es en opinión del Magistrado autor del citado voto particular, «el presupuesto que ha de tenerse en cuenta para admitir o negar la existencia de nexo causal entre la inactividad administrativa y la lesión del derecho fundamental alegado». En suma, la cuestión que se nos traslada es «si a un Ayuntamiento corresponde, en uso de sus potestades, impedir que actuaciones de particulares, sujetas a autorización o licencia administrativa, perturben los derechos fundamentales aquí convocados y si el ejercicio de tales potestades se convierte en obligatorio cuando la agresión a los derechos fundamentales alcanza un determinado nivel de gravedad».

La última resolución del TC por el momento sobre esta materia se contiene en la STC 150/2011, relevante por diversas razones. De un lado, porque nos encontramos ante un recurso de amparo mixto, en el que son objeto de consideración tanto las posibles violaciones de derechos imputables a las administraciones, como las resoluciones judiciales previas. De otro lado, porque aun teniendo presente nuestro Alto Tribunal la jurisprudencia del TEDH, se reitera una interpretación autónoma y, finalmente, por las posiciones que se reflejan en los votos particulares no concurrentes con el sentir mayoritario del Tribunal. 
Una primera apreciación que se realiza, retomando argumentaciones ya contenidas en la jurisprudencia anterior (STC 119/2001), permite analizar exclusivamente «aquellas omisiones que se traduzcan en la lesión de un derecho fundamental de los invocados», sin consideración alguna relativa a la calidad de vida existente que se estima dentro de la esfera del artículo $45 \mathrm{CE}$. Por tanto, el análisis que lleva a cabo el TC se circunscribe al ámbito de «la posible incidencia que el ruido tiene sobre la integridad real y efectiva de los derechos fundamentales alegados por el recurrente», esto es, establecer en qué condiciones puede el ruido ocasionar lesiones en los derechos fundamentales a la integridad física y moral (art. $15 \mathrm{CE}$ ), a la intimidad personal y familiar y a la inviolabilidad del domicilio (arts. 18.1 y 18.2 CE).

Por otra parte, el TC se hace eco de la repercusión de la contaminación acústica en el legítimo ejercicio del derecho fundamental y de modo complementario asume la percepción del impacto que puede tener para la intimidad personal y familiar así como para la inviolabilidad del domicilio. Esta percepción ha permitido determinar a nuestro Alto Tribunal cómo «una exposición prolongada a unos determinados niveles de ruido, que puedan objetivamente calificarse como evitables e insoportables, ha de merecer la protección dispensada al derecho fundamental a la intimidad personal y familiar, en el ámbito domiciliario», siempre que incidan en modo considerable en el libre desarrollo de la personalidad y »la lesión o menoscabo provenga de actos u omisiones de entes públicos a los que sea imputable la lesión producida» (STC 16/2004).

Debemos recordar que el TC se refiere a determinados «daños ambientales» cuando hace referencia a la jurisprudencia del TEDH. Se hace hincapié, eso sí en que no ponen en peligro la salud de las personas pero si pueden dar lugar a privaciones «del disfrute de su domicilio» y como consecuencia de ello, «atentar contra su derecho al respeto de su vida privada y familiar». Quizá el avance significativo en la construcción de un tipo de injerencia viene dado por el reconocimiento de la vulneración sea esta «material o corporal», o bien «inmaterial o incorporal»(Caso Moreno Gómez). Es a partir de aquí que ruidos, emisiones, olores, pueden atentar contra el derecho al respeto del domicilio y, si dicha vulneración es grave, incluso puede suponer la privación de este derecho en la medida en que le impide su disfrute al titular del mismo.

Nuestro Alto Tribunal no ignora que el ruido puede tener incidencia en «otros valores y derechos constitucionales» o legales, pero cuya protección se llevaría a cabo por cauces diferentes al amparo constitucional. En suma, el objetivo de este enjuiciamiento se debe ceñir a «la posible incidencia que el ruido tiene sobre la integridad real y efectiva de los derechos fundamentales» que en el recurso se alegan. Para el TC «cuando la exposición continuada a unos niveles 
intensos de ruido ponga en grave peligro la salud de las personas, esta situación podrá implicar una vulneración del derecho a la integridad física y moral (art. $15 \mathrm{CE}$ )». Evidentemente el riesgo o daño a la salud debe ser cualificado.

Una vez afirmado que el ruido puede suponer una lesión a los derechos fundamentales, se interna el Tribunal en la prueba al objeto de constatar, en su caso, «si la contaminación acústica sufrida» ha supuesto una puesta en peligro grave e inmediato de la salud o que dicho nivel de ruido impidiese o dificultase el libre desarrollo de su personalidad. Resulta pues «indispensable» que el recurrente «hubiese acreditado bien que padecía un nivel de ruidos que le producía insomnio y, en consecuencia, ponía en peligro grave e inmediato su salud, bien que el nivel de ruidos existente en el interior de su vivienda era tan molesto que impedía o dificultaba gravemente el libre desarrollo de su personalidad». Por tanto, resolverá el TC desestimando el recurso de amparo, ya que no ha resultado acreditada una lesión real y efectiva de derechos con prueba individualizada, más allá del hecho de que el demandante de amparo residiera en una zona declarada acústicamente saturada.

Pero aun cuando se trata de una sentencia de pleno, junto al parecer mayoritario del Tribunal debemos detenernos en los dos votos particulares formulados que reflejan concepciones diversas sobre el procedimiento de protección, los derechos en juego y la solución finalmente alcanzada por el TC.

El voto particular suscrito por el Magistrado Aragón Reyes recoge un punto de vista diverso de la línea argumental hasta ahora objeto de consideración. El contenido de este voto reviste un especial interés ya que no sólo evita cualquier extensión en el entendimiento del principio rector ex artículo $45 \mathrm{CE}$ a la protección conferida a los derechos fundamentales, sino que se aparta expresamente del antecedente jurisprudencial que supuso la STC 119/2001. En efecto, para este Magistrado, el derecho frente al ruido ex artículo 8.1 CEDH, aquí comentado al hilo de la jurisprudencia del TEDH en su dimensión de afectación a la vida privada, aunque «sea un derecho subjetivo aplicable por los Jueces y Tribunales de Justicia españoles de conformidad con lo dispuesto en el artículo 96.1 CE, no significa en modo alguno que, además, sea en España un derecho fundamental, en el sentido constitucional del término, tutelable en amparo por el TC, (...) que parte de una interpretación insostenible (...) de la previsión contenida en el artículo 10.2 CE».

La discrepancia del Magistrado Aragón Reyes lo es con la fundamentación de la previa STC 119/2001 y no comparte la asunción «acrítica» por nuestro Alto Tribunal de la resolución del Tribunal de Estrasburgo en el Caso Moreno Gómez en la citada sentencia, al margen de entender que «resulta cuanto menos discutible que un bien jurídico como la salud, configurado como un principio 
rector por el artículo 43.1 CE, pueda alcanzar protección mediante recurso de amparo ante el TC, a través de una muy difícil extensión del contenido o alcance del derecho fundamental a la integridad física y moral».

Un primer motivo esgrimido por este Magistrado afecta al bien jurídico salud que aparece afectado por la exposición continuada a ruidos intensos, pues en todo caso siempre estaremos en presencia de un principio rector y, por ello, «resulta cuando menos discutible» que se pueda beneficiar de la protección que implica el recurso de amparo, ya que resulta, en palabras del Magistrado, «de una muy difícil extensión del contenido o alcance del derecho fundamental a la integridad física y moral».

No se discute el razonamiento realizado por el TEDH en orden a la protección de la vida privada y familiar frente al ruido ambiental en virtud de la interpretación que se ha realizado del artículo 8. CEDH. Ahora bien, entiende el Magistrado que no cabe colegir de dicha interpretación la consideración como derecho fundamental y, por ello, susceptible de amparo constitucional. La clave se encuentra en la interpretación del alcance que se conceda al artículo 10.2 CE que entiende el Magistrado Aragón Reyes no es una cláusula aditiva que haga posible, a la luz de la jurisprudencia del Tribunal de Estrasburgo en relación con un derecho proclamado en el $\mathrm{CEDH}$, «ampliar el listado de derechos fundamentales» o «mutar la naturaleza» de los derechos reconocidos en la Constitución española. El recto entendimiento de dicho precepto se concretaría en su carácter interpretativo que «únicamente impone que los derechos fundamentales y libertades reconocidos en la Constitución (...) se interpreten de conformidad con lo establecido en los Tratados Internacionales en materia de derechos humanos ratificados por España» ${ }^{54}$.

En tercer lugar, la discrepancia se extiende a las consecuencias que se extraen de la jurisprudencia del TEDH como de los precedentes del Alto Tribunal en esta materia, de cuyo criterio expresamente se separa el Magistrado, toda vez que considerar que a través del ruido ambiental «se pueda lesionar los derechos a la intimidad personal y familiar y la inviolabilidad de domicilio, incurre en un grave error conceptual, pues implica una incorporación encubierta de nuevos derechos» (derecho frente al ruido o derecho al silencio) o cuando menos una radical alteración del contenido de los derechos fundamentales reconocidos en el artículo 18.1 y 2 CE.

54 «El artículo 10.2 no permite incorporar nuevos derechos fundamentales y libertades públicas en la Constitución, ni alterar la naturaleza de los reconocidos expresamente en la misma ampliando artificialmente su contenido o alcance, ni, por tanto, extender la tutela mediante el recurso de amparo a otros derechos y libertades, más allá de lo preceptuado en el artículo 53.2 CE.» 
El voto particular formulado por el Magistrado Ortega Álvarez hace hincapié en la inexistencia de un reconocimiento expreso en el $\mathrm{CEDH}$ de un derecho al medio ambiente como ha recogido la jurisprudencia del TEDH, si bien »cuando un ruido u otro contaminante afecta a un individuo, puede plantearse un problema en virtud del artículo 8 del Convenio». La discrepancia del Magistrado con la mayoría del Pleno en esta sentencia radica en que no realiza una interpretación compatible del artículo 18.1 y 2 CE con el artículo 8 del CEDH, tal y como ha sido interpretado por el TEDH. La formulación que se propone sería la de un derecho fundamental derivado de la jurisprudencia del Tribunal de Estrasburgo y del artículo 18.1 y 2 en conexión con el artículo 10.2 CE a la inexistencia de ruido en el entorno sin necesidad de prueba en el interior de la vivienda.

Podemos concluir tras el análisis de la jurisprudencia más relevante del TEDH y del TC en materia de ruido y contaminación acústica y su incidencia en la intimidad personal e inviolabilidad domiciliaria, la relativa virtualidad de esta jurisprudencia del Tribunal de Estrasburgo en el reconocimiento por nuestro Alto Tribunal de la protección del medio ambiente, ya que evidencia la relevancia alcanzada por el medio ambiente, en la medida en que se ha llegado a afirmar que «estos derechos han adquirido (...) una dimensión positiva en relación con el libre desarrollo de la personalidad, orientada a la plena efectividad de estos derechos fundamentales». En el mismo sentido, es positiva la mención a su protección no sólo frente a injerencias externas «sino también frente a los riesgos que puedan surgir en una sociedad tecnológicamente avanzada». Ahora bien, el carácter condicional del tiempo verbal empleado no es gratuito ya que el Tribunal parece consciente de la imprevisibilidad de dichos riesgos y la necesidad de otorgar algún tipo de protección frente a los mismos.

El objeto de este apartado era dilucidar si conlleva consecuencias relevantes dicha jurisprudencia para superar la interpretación del artículo 45 CE más allá de su entendimiento como principio rector o derecho constitucional. Se ha podido constatar como nuestro Alto Tribunal le ha negado expresamente la calificación de derecho fundamental (STC 199/1996), limitándose a confirmar su carácter de principio rector, del que puede derivar una cierta tutela judicial, sin perjuicio de los instrumentos normativos puestos en marcha por el legislador para permitir una tutela efectiva del medio ambiente 55 .

55 «El medio ambiente protegido es también el hábitat de una o varias personas (...) éste es el lugar en el que se desarrolla una parte importante de la vida humana y, en este sentido también forma parte del medio ambiente. Las personas tienen, por tanto, derecho a que la porción del medio 


\section{EL DEBER DE PROTECCIÓN DEL MEDIO AMBIENTE}

\section{El deber de todos de conservar el medio ambiente}

Hemos señalado con anterioridad la dificultad de concretar el mandato constitucional a los ciudadanos y a los poderes públicos de proteger el medio ambiente. Sin duda conlleva menor dificultad la caracterización del artículo 45 CE como un deber constitucional, que se impone a los poderes públicos y a los ciudadanos $^{56}$, un deber de conservación, aun cuando tampoco puedan precisarse mucho más sus perfiles. Como señalara Rubio Llorente los deberes constitucionales «sirven finalidades o intereses muy diversos» que en el caso del deber de conservación del medio ambiente no resultan tan evidentes ${ }^{57}$. Así se ha apuntado que serían destinatarios de este deber genérico de conservación tanto los ciudadanos para la protección de este interés colectivo ${ }^{58}$ como los poderes públicos, especialmente el legislador por cuanto el mandato constitucional incluye el desarrollo del mismo a cuyo cumplimiento quedan obligados los ciudadanos ${ }^{59}$. No obstante es evidente que en este deber de conservación se aprecia una suerte de deber de solidaridad tanto individual como colectivo de la ciudadanía ${ }^{60}$, que afecta no sólo a la generación presente sino también a las futuras. Por tanto, la necesaria interpositio legislatoris cobra igualmente pro-

ambiente en el que viven una parte considerable de su vida esté protegido de todo ruido que no pueda ser considerado socialmente adecuado, como los que están legal y reglamentariamente proscritos» (STS de 28 de abril de 2016).

56 «La obligación de proteger el medio ambiente constituye, en varios sentidos, un principio fundante de la legitimidad de la actuación estatal», Simón YAIZA, F., Medio Ambiente y derechos fundamentales, Centro de Estudios Políticos y Constitucionales, Madrid 2012. Op. cit., p. 95.

57 Rubio Llorente, F., «Los deberes constitucionales», Revista Española de Derecho Constitucional, 2001, núm. 62. Op. cit., p. 21. En efecto, este autor se refiere a los «deberes anómalos» que se imponen por diversas finalidades no siempre fáciles de discernir. Para añadir a continuación que «El contenido jurídicamente decisivo del artículo 45 de la Constitución es, en consecuencia, el que erige esta protección en finalidad necesaria de los poderes públicos, pues sólo en la medida en la que estos lo definen, al adoptar medidas concretas para protegerlo, adquiere realidad el medio ambiente que todos tienen el derecho de gozar y el deber de conservar». Ibídem, p. 33.

58 Para Moret Millás, se trata de «deberes públicos de prestación» que suponen para los ciudadanos verdaderas obligaciones jurídicas que se concretan en «actividades personales necesarias para la satisfacción de las necesidades generales», en este caso la conservación del medio ambiente. Moret Millás, V., «Los deberes constitucionales», Revista de las Cortes Generales, núm. 86, 2012

59 Varela Díaz, S., «La idea de deber constitucional», Revista Española de Derecho Constitucional, núm. 4, 1982.

60 LANCHESTER, F., «Los deberes constitucionales en el derecho comparado», Revista Española de Derecho Constitucional, núm. 13, op. cit., pp. 67-68. 
tagonismo en los apartados segundo y tercero de este precepto. Es claro que a partir del artículo 9.1 CE existe una obligación general de cumplimiento del ordenamiento jurídico, si bien hemos de reconocer que este deber de conservar aparece formulado como una proposición jurídica incompleta ${ }^{61}$. El mandato constitucional es inequívoco pero corresponderá al legislador precisar el resultado que se debe obtener, así como los medios con los que se ha de contar para su consecución por lo que se ha destacado «la centralidad del deber» que se contiene en este precepto ${ }^{62}$. Solo a través del desarrollo legislativo se podrán reconocer deberes vinculados al artículo 45 CE pero necesariamente lo serán de configuración legal ${ }^{63}$. En este sentido cobra toda su actualidad el debate en torno al deber genérico de protección ambiental y, si a partir de aquél, cabe hablar de la generación de una obligación jurídica, esto es, si jurídicamente es exigible, accionable ese deber con suficiente fundamentación constitucional. Entendemos que estamos ante un deber genérico pero que sólo deriva en una obligación jurídica en la medida en que el legislador ha precisado su contenido, por lo que el análisis del desarrollo legislativo es crucial para alcanzar un mayor nivel de concreción. En todo caso, ese deber se concretará en obligaciones de abstención de determinadas conductas conducentes a causar daños ambientales en el caso de las personas, si bien en algunos supuestos el legislador prevé conductas positivas bien de los titulares de predios o de actividades económicas con repercusiones ambientales, como de los poderes públicos ${ }^{64}$. Ahora bien, hemos de diferenciar el deber de los ciudadanos de protección del medio ambiente de aquel otro que recae sobre los poderes públicos.

Respecto de los deberes que ha impuesto el legislador a los particulares así como a los operadores económicos cabe referirse brevemente a la Ley 26/2007, de Responsabilidad Ambiental y su reforma que implica, entre otras, la obligación a «Los operadores de las actividades económicas o profesionales incluidas en esta ley (que) están obligados a adoptar y a ejecutar las medidas de prevención, de evitación y de reparación de daños medioambientales y a sufragar sus costes, cualquiera que sea su cuantía, cuando resulten responsables de los mismos».

61 Balaguer Callejón, F., Manual de Derecho Constitucional II, Tecnos 2010. Madrid.

62 «Hay un mandato dirigido a los ciudadanos que precisa de la efectividad por parte de los poderes públicos». Betancor Rodríguez, A., Derecho Ambiental. Op. cit., p. 519.

63 «Los deberes que para los individuos resultan de la legislación protectora del medio ambiente son simplemente medios que la norma emplea para asegurar su objetivo directo, que es la de proteger determinadas realidades físicas». Rubio Llonente, F., «Los deberes constitucionales», Revista Española de Derecho Constitucional, núm. 62, 2001. Op. cit., p. 34.

64 STC 64/1982. 
Estamos pues en presencia de un verdadero deber legal expresamente señalado por el legislador.

En el mismo sentido, la Ley 34/2007 de Calidad del Aire y Protección Atmosférica se refiere a obligaciones de los titulares de las instalaciones donde se desarrollen actividades potencialmente contaminadoras de la atmósfera. También se contiene un claro mandato en la Ley de respeto y contribución a la preservación del medio ambiente y el paisaje así como de abstención de llevar a cabo actuaciones que contaminen el aire, el agua, el suelo y el subsuelo (art. 6 del Real Decreto Legislativo 7/2014 por el que se aprueba el texto refundido de la Ley de suelo y Rehabilitación Urbana).

El incumplimiento del deber de protección ambiental por los ciudadanos puede ser analizado también desde la óptica del derecho penal. En efecto, el legislador ha llevado a cabo la tipificación penal de determinadas conductas contrarias al deber de protección del medio ambiente así como regulado la responsabilidad ambiental. A través de la Ley Orgánica 8/1983 se introdujo en nuestro ordenamiento jurídico el delito contra el medio ambiente. En efecto, la comisión de delito ecológico se penaba con la privación de libertad y multa hasta de 5.000.000 pts. La descripción del tipo comprendía conductas que contraviniendo las Leyes o Reglamentos protectores del medio ambiente causasen emisiones o vertidos contaminantes, constituyendo infracciones de las normas correspondientes con grave riesgo para la salud de las personas o que pudieran perjudicar gravemente las condiciones de la vida animal, bosques, espacios naturales o plantaciones útiles. Se incluía como conducta agravada el funcionamiento de industrias sin autorización como las de aquéllas que, aun con la autorización preceptiva realizasen actividades que no se sujetasen a las órdenes expresas de la Administración relativas a la corrección o suspensión de la actividad contaminante. La pena se incrementaba si mediare riesgo de deterioro irreversible o catastrófico.

El Código Penal vigente ha intensificado la persecución penal de los ilícitos contra el ambiente desde una perspectiva amplia, toda vez que se comprenden en el Título XVI los delitos relativos a la ordenación del territorio, contra los recursos naturales y el medio ambiente (Cap. III) y los relativos a la protección de la flora y de la fauna (Cap. IV), que posibilitan un tratamiento diferenciado de las conductas tipificadas como ilícitos penales. Si bien en determinadas ocasiones la tipificación de las conductas como ilícitos penales mantiene un referente normativo ajeno al propio Código, toda vez que la conducta que se define lo es por contravenir «las leyes o disposiciones de carácter general», protectoras del medio ambiente tanto estatales como autonómicas. Aunque el TC se ha manifestado sobre la constitucionalidad de esta técnica de 
norma penal en blanco ${ }^{65}$ por remisión al legislador no penal, lo cierto es que esta cuestión ha generado un margen de inseguridad jurídica indudable. Así constituirán conductas delictivas las realizadas contraviniendo las leyes o disposiciones de carácter general protectoras de las especies de flora o fauna (art. $333 \mathrm{CP}$ ), la pesca o caza de especies amenazadas, las actividades que impidan o dificulten su reproducción o migración, contraviniendo la normativa correspondiente (art. $334 \mathrm{CP}$ ), o cuando no esté expresamente autorizada su caza o pesca por las normas específicas en la materia (art. 335 CP). Se considera como conducta agravada, aquella atentatoria contra el medio ambiente que se realiza en un espacio protegido, por la singularidad del mismo, que ha motivado su declaración como tal (art. $330 \mathrm{CP}$ ).

Constituye una innovación la introducción de responsabilidad de los funcionarios de la Administración que, a través de la autorización de actividades con repercusión ambiental, o con conocimiento de infracciones ambientales causadas por aquéllas con ocasión de tareas de inspección, no informen pertinentemente de las mismas (art. 329 CP). No obstante la redacción del precepto presenta alguna dificultad interpretativa respecto a la determinación de la responsabilidad si la autorización para la actividad contaminante se concede por órganos colegiados.

En todo caso hay que atender a la caracterización de los delitos toda vez que las conductas pueden ser de mero peligro o de resultado ${ }^{66}$. Si se repara en los delitos contra los recursos naturales y el medio ambiente, la conducta objeto de la sanción penal se prefigura por el peligro que para el medio ambiente tienen las emisiones o vertidos que se puedan realizar a la atmósfera, suelo, subsuelo, aguas interiores o marítimas. Los ilícitos penales contra la protección de la fauna y la flora quedan sujetos a la producción de un resultado, de un perjuicio directo e inmediato. Además, la dificultad de determinar los elementos probatorios así como la relación de causalidad pueden entorpecer la actuación judicial, aun cuando la inexistencia de nexo causal no debe constituir un supuesto de indefensión, siempre que el órgano jurisdiccional constatase la existencia en la causa de prueba constitucionalmente válida que variará necesariamente si el ilícito es de riesgo o resultado ${ }^{67}$. No obstante, persiste la dificultad de determinar la respon-

65 STC 127/1990.

66 Una percepción dinámica de los atentados al ambiente por parte de los órganos jurisdiccionales se constata, entre otras, ante condenas en relación con la expulsión a la atmósfera de gases contaminantes procedentes de aparatos de frío (STS de 31 de mayo de 2016).

67 Entre otros, «La valoración del bien ambiental como elemento del dictamen pericial en el delito contra el medio ambiente y la ordenación del territorio», ABBAD, T., y GUTIÉrREZ, G., Actualidad Jurídica ambiental n. ${ }^{\circ} 48,1$ de julio de 2015. 
sabilidad ante determinados desastres ambientales ${ }^{68}$ o la ejecución de condenas en materia ambiental ${ }^{69}$.

Respecto a la responsabilidad ambiental esta viene contemplada en la Ley 26/2007, en la que se regula la responsabilidad de los operadores de prevenir, evitar y reparar los daños medioambientales, de conformidad con el artículo 45 CE y con los principios de prevención y de que «quien contamina paga». En todo caso hay que lamentar que el Real Decreto 183/2015 haya reducido las actividades que quedan sujetas a la constitución de una garantía financiera con la crisis económica como justificación de esta medida.

\section{LAS OBLIGACIONES DE LOS PODERES PÚBLICOS PARA LA PROTECCIÓN DEL MEDIO AMBIENTE}

Si bien es bastante complejo precisar qué tipo de consecuencias, prestaciones o acciones se han de llevar a cabo por los poderes públicos en desarrollo de este mandato constitucional, entendemos necesario progresar en una interpretación dinámica del Capítulo III en la que se supere el entendimiento del mismo como un contenido mínimo ${ }^{70}$ que imponga a los poderes públicos una actuación sucinta en la materia, si bien para ello es necesario alejarse de ciertas falacias sobre los principios rectores de la política social y económica como la relativa a la consideración de que «los derechos sociales no son exigibles y el resto de derechos

68 El proceloso camino seguido desde que se produjo el vertido por rotura de la balsa de estériles de la empresa Boliden en Alnazcollar (Sevilla), ha consumido 18 años, y aún no ha culminado en la vía jurisdiccional, pues pende la tramitación en vía civil de la exigencia de responsabilidad por la Junta de Andalucía a la entidad mercantil Boliden Aprisa, S. L., propietaria de la mina. El TS en sentencia de 28 de diciembre de 2011, concluyó conforme a pronunciamientos anteriores, que la rotura de la balsa tuvo lugar por no incorporar el proyecto técnico de construcción determinadas prescripciones, si bien no cabía concluir que «los vicios en la construcción de un edificio se proyecten sobre la administración que concedió la correspondiente licencia de obras».

69 La inicial STS de 13 de octubre de 2008 relativa a la reducción de un número determinado de vuelos sobre una población cercana al aeropuerto de Barajas aún no ha sido ejecutada en su totalidad como se ha acreditado en la reciente STS de 3 de abril de 2017.

70 En este sentido Cascajo Castro, J. L., «Derechos Sociales», en Derechos Sociales y Principios Rectores, Actas del IX Congreso de la Asociación de Constitucionalistas de España, Cascajo Castro, J. L., Terol Becerra, M., Domínguez Vila, A., Navarro Marchante, V. (Coords.) Valencia, 2012, Tirant lo Blanch. Op. cit. p. 31. 
sí» ${ }^{71}$. Cobra así protagonismo el control judicial de las actuaciones de los poderes públicos como instrumento de «exigibilidad» de los deberes de éstos ${ }^{72}$.

En todo caso compete al legislador precisar en qué conductas se concreta dicho mandato, incluso cabe imaginar como la omisión por el legislador del mismo podría constituir una violación del artículo 45 CE. Quizá un somero repaso a la legislación ambiental permita determinar claros objetivos de los que puede derivarse una obligación real exigible a los poderes públicos ${ }^{73} \mathrm{y}$, por tanto, un mayor nivel de concreción ${ }^{74}$.

El deber de proteger un medio ambiente adecuado para el desarrollo de la persona se ha concretado por el legislador ${ }^{75}$ especialmente en la Ley 42/2007, del Patrimonio Natural y de la Biodiversidad, a través de la regulación del régimen jurídico básico de la conservación, uso sostenible, mejora y restauración de éstos. Con este punto de partida el legislador ha afirmado que «El patrimonio natural y la biodiversidad desempeñan una función social relevante por su estrecha vinculación con el desarrollo, la salud y el bienestar de las personas y por su aportación al desarrollo social y económico» (art. 4.1). La vertiente del deber de conservación alcanza a la obligación por parte de las Administraciones Públicas de velar por la conservación y la utilización racional del patrimonio natural en todo el territorio nacional (art. 5.1), atendiendo a la «prevalencia de la protección ambiental sobre la ordenación territorial y urbanística», así como al principio

71 Rey Martínez, F., «Derribando falacias sobre derechos sociales», en Derechos Sociales y Principios Rectores, Actas del IX Congreso de la Asociación de Constitucionalistas de España, CAScajo Castro, J. L., Terol Becerra, M., Domínguez Vila, A., Navarro Marchante, V., (Coords.) Valencia, 2012, Tirant lo Blanch. Op. cit., p. 635.

72 Alegre Martínez, M. A., «Los deberes en la Constitución española: esencialidad y problemática». Teoría y Realidad Constitucional. Op. cit., p. 289.

73 Así el mandato de la ley de Costas recae sobre la defensa de la integridad del dominio público marítimo-terrestre, «la preservación de sus características y elementos naturales», así como la prevención frente a los perjuicios que se pudieran causar por obras e instalaciones que se llevasen a cabo en el mismo (art. 10). En el caso de la legislación de aguas se enuncia como principio que ha de guiar la actuación de los poderes públicos «Proteger y mejorar el medio acuático estableciendo medidas específicas para reducir progresivamente los vertidos, las emisiones y las pérdidas de sustancias prioritarias, así como para eliminar o suprimir de forma gradual los vertidos, las emisiones y las pérdidas de sustancias peligrosas prioritarias» (art. 92.c).

74 «Con el fin de clarificar qué aporta el desarrollo legislativo a la idea —así como a la exigibilidad y eficacia - del deber constitucional». Alegre Martínez, M. A., «Los deberes en la Constitución española: esencialidad y problemática». Teoría y Realidad Constitucional. Op. cit., p. 287.

75 Gavara de Cara habla de «Configuraciones normativas abiertas». Gavara DE CARA, J. C., «La vinculación positiva de los poderes públicos a los derechos fundamentales», Teoría y Realidad Constitucional, núm. 20, 2007. Op.cit., p. 316. 
de precaución que ha de informar cualquier intervención que se pueda llevar a cabo sobre espacios naturales o especies silvestres.

Además se introduce una visión transversal de la protección medioambiental de modo que se lleve a cabo por todos los poderes públicos en su ámbito competencial correspondiente «la integración» de estos objetivos ambientales en la toma de decisiones en el ámbito político, económico y social, así como la participación justa y equitativa en el reparto de beneficios que se deriven de la utilización de los recursos genéticos. Estamos pues ante un claro mandato legal a los poderes públicos que, en este caso sí, creemos accionable ante los tribunales de justicia su incumplimiento por aquéllos ${ }^{76}$. Ocurre igual con la exigencia a «todos los poderes públicos» de velar por la conservación de los parques nacionales (art. 2 ) que el legislador ha recogido como deber (art. 2), con la correlativa previsión de la acción pública para «exigir ante los órganos administrativos y los tribunales de justicia la estricta observancia» de dicha Ley 30/2014 de Parques Nacionales (art. 39).

Una vez realizada una descripción teórica de algunos de los parámetros en los que se sitúa la protección ambiental en España y ante la imposibilidad material de profundizar en el ámbito autonómico, resulta de mayor interés el análisis de la aplicación judicial de la tutela ambiental. De un lado, para constatar la virtualidad del derecho a disfrutar del medio ambiente y su efectividad. De otro lado, como deber de protección del medio ambiente, el análisis de algunos casos resueltos por nuestros órganos jurisdiccionales, nos permitirá reflexionar sobre la realidad actual del cumplimiento por los poderes públicos del mandato del artículo 45.2 CE. Son, sin duda, las administraciones públicas las que, dentro de la ejecución de sus competencias respectivas, en ocasiones han podido subvertir el propio ordenamiento jurídico desconociendo o vulnerando abiertamente el mandato constitucional de protección del medio ambiente.

A partir de la imposición a los poderes públicos del deber de velar por la utilización racional de los recursos naturales con el fin de proteger y mejorar la calidad de vida y defender y restaurar el medio ambiente, se ha señalado la existencia de un derecho de la función pública de protección de los recursos naturales, para que las políticas públicas «tengan en cuenta la situación de los recursos naturales afectados» ${ }^{77}$. Pero no parece que en todas las ocasiones se hayan ateni-

76 Pero como ha señalado Alegre Martínez, «la difícil exigibilidad de los deberes, sobre todo la de su cumplimiento por parte de los poderes públicos, echa por tierra cualquier intento de elaborar una teoría sobre los mismos». Alegre Martínez, M. A., «Los deberes en la Constitución española: esencialidad y problemática». Teoría y Realidad Constitucional, Op. cit., p. 290.

77 López RAmón, F. «El derecho ambiental como derecho de la función pública de protección de los recursos naturales», en AAVV La protección jurídica del medio ambiente, Aranzadi, Pamplona, 1997. Op. cit., p. 109. 
do las Administraciones a dicha exigencia constitucional y legal. Es más, a veces, a través de la aprobación de leyes «singulares» o con disposiciones de los ejecutivos autonómicos, no sólo se ha puesto en entredicho el cumplimiento del mandato del artículo $45 \mathrm{CE}$, sino también el control por los órganos jurisdiccionales de determinados proyectos sin justificación suficiente.

Recogemos a continuación algunas de las resoluciones que pueden ayudar a conocer el nivel de cumplimiento por los poderes públicos del mandato constitucional del artículo 45.2 CE. No abordaremos el análisis de políticas públicas ambientales, sino los mecanismos de control de la legalidad de la actuación de las administraciones, para evitar que la discrecionalidad conlleve la falta de motivación de determinadas decisiones y actos administrativos vulneradores de la protección ambiental. Incluso es sorprendente como a través de la aprobación de determinados instrumentos normativos estatales o autonómicos se ha podido incurrir en una evidente vulneración de la protección medioambiental.

En múltiples ocasiones, la legislación de costas, suelo, aguas, condiciona claramente la planificación del territorio y sus usos con consecuencias, entre otras, en la ubicación de proyectos estratégicos para el desarrollo de la comarca o el trazado de nuevas infraestructuras y vías de comunicación. Es especialmente relevante en este sentido, por su incidencia en la ordenación del territorio y la planificación urbana, la previsión de la Ley 22/1988, de Costas vigente hasta su reforma en 2013 , relativa a la servidumbre de protección sobre la zona marítimoterrestre. Pues bien, su nivel de observación y cumplimiento ha sido muy débil, ya que la transformación del litoral se ha producido en numerosas ocasiones a través de desarrollos urbanísticos transgresores de dicha norma. Ocurre también que el legislador autonómico, al hilo de la regulación específica sobre urbanismo y ordenación del territorio ha previsto instrumentos que pudieran soslayar las exigencias derivadas de la Ley de Costas. Este es el caso del denominado Proyecto de «las Aletas», que constituye un ejemplo significativo de lo que ha sucedido con la planificación de actividades de carácter económico con incidencia en el litoral y de difícil compatibilidad con la normativa de $\operatorname{costas}^{78}$.

78 STS de 19 de octubre de 2009 por la que se anula la declaración de una zona de reserva de 287 hectáreas de suelo de dominio público marítimo terrestre en el área de Las Aletas, Puerto Real (Cádiz). Pues bien, ocho años más tarde el Tribunal Supremo se ha vuelto a pronunciar al respecto de la reserva de suelo con un fallo que reitera no queda acreditado que este proyecto «no puede tener otra ubicación» pese a que fue objeto de reconsideración en un nuevo acuerdo del Consejo de Ministros en el año 2015. En esta ocasión el Tribunal Supremo ha señalado que «ninguna justificación existe de que la opción elegida tuviera algún punto de conexión con la necesidad de ocupar el demanio en función de la naturaleza de la actividad o de las instalaciones. En segundo lugar, el hecho de que se hayan discriminado usos con la finalidad de ocupar una menor super- 
La puesta en marcha de proyectos de contenido económico con incidencia en la ordenación del territorio pueden no solo entrar en conflicto con la legalidad de la zona marítimo-terrestre, sino incluso colisionar con la regulación de los espacios naturales declarados protegidos contiguos a dicha zona. Además, se debe resaltar que como consecuencia de la distribución territorial del poder operada por el Estado de las Autonomías, las Comunidades Autónomas han propiciado el impulso de un nuevo ámbito legislativo de protección del medio ambiente, a través de las normas aprobadas por los parlamentos autonómicos relativas a la protección ambiental como con normas adicionales de protección. Este proceso se ha visto acompañado de determinadas políticas públicas orientadas a la declaración de los espacios protegidos y su gestión sostenible, sin embargo cabe apreciar algunas contradicciones a la hora de hacer compatible el desempeño de sus competencias ambientales con el impulso del desarrollo económico adoptado por dichas administraciones, que ponen de manifiesto la presión de los proyectos «turísticos» sobre los espacios costeros, incluso cuando previamente han sido declarados protegidos por las administraciones autonómicas y el riesgo de reversión ambiental sobre los mismos ${ }^{79}$.

La legislación singular en apoyo de proyectos de desarrollo ha permitido constatar en determinadas ocasiones la ponderación entre la protección ambiental y el desarrollo económico. Así, respecto de la ordenación del territorio y la planificación urbanística, concurren diversos mandatos del legislador de obligado cumplimiento para las administraciones que no pueden ser desatendidos en atención al legítimo ejercicio de una competencia en el ámbito de su autonomía institucional. Sin embargo, no deja de ser cierto que la realidad en cuantiosas ocasiones muestra cómo se produce un quebrantamiento de la legalidad ambiental en el ámbito urbanístico y/o con la justificación en el impulso económico y desarrollo de infraestructuras o núcleos de población vinculados a proyectos concretos a través de la aprobación mediante Decreto del gobierno autonómico

ficie de dominio público, no es razón para justificar la necesidad de ocupar la superficie afectada» (STS de 31 de marzo de 2017).

79 Constituye un claro ejemplo del incumplimiento por parte de las administraciones del deber de proteger el medio ambiente en un espacio natural protegido el denominado caso Algarrobico. Es por ello que el Tribunal Supremo ha reiterado en la resolución de este asunto la «superioridad del planeamiento medio ambiental sobre el urbanístico (reflejo de la preponderancia de los valores medioambientales sobre los de mera ordenación del territorio (...) sino que el planeamiento urbanístico ha de adaptarse a lo establecido en el planeamiento ambiental» (STS de 10 de febrero de 2016). En el mismo sentido se puede citar el proyecto de desarrollo económico sobre el espacio natural protegido de Cabo Cope (Murcia), cuyo instrumento normativo de desclasificación parcial de un espacio protegido por el Parlamento de Murcia fue declarado inconstitucional (STC 234/2012). 
de un el Proyecto de Interés Regional. Pues bien, aun cuando el tribunal competente reconoce a la Administración un margen de discrecionalidad para la elección del terreno adecuado para el desarrollo del proyecto, se reafirma a continuación que queda siempre sujeto al control jurisdiccional y, por ello, se examina la oportunidad de que un terreno clasificado previamente como suelo no urbanizable común "pase a tener la clasificación de urbanizable a fin de hacer posible su incorporación al proceso urbanizador» ${ }^{80}$.

El desarrollo de proyectos de ocio y deporte ha estado entre las iniciativas adoptadas por las administraciones autonómicas y municipales, si bien la impugnación de los acuerdos aprobatorios de dichos proyectos ante la jurisdicción y, su ulterior paralización como consecuencia de las resoluciones de aquélla, ha dado lugar a la adopción por algunos parlamentos autonómicos de normas orientadas a soslayar las resoluciones judiciales y sacar adelante los proyectos por sus teóricos beneficios sociales para la Comunidad afectada. En ocasiones, a través de la intervención del legislador autonómico, en el ámbito de sus competencias, se ha acudido a la aprobación de una ley singular para eludir las consecuencias derivadas de estos pronunciamientos contrarios a dichos proyectos $y$, con justificación en los beneficios para el desarrollo económico con el objeto de posibilitar la ejecución de aquéllos. En estos casos, el canon de constitucionalidad que debe utilizar nuestro Alto Tribunal «al ejercer su función de control de este tipo de leyes es el de la razonabilidad, proporcionalidad y adecuación» ${ }^{81}$.

80 El Proyecto de Interés Regional promovido por Marina DE VAldeCañas, S. A. «consistente en la recalificación y ordenación de terrenos situados en el embalse de Valdecañas, con destino a la construcción del complejo turístico, de salud, paisajístico y de servicios Marina Isla de Valdecañas, en los términos municipales de el Gordo y Berrocalejo, en la provincia de Cáceres. Recurrido el Decreto del Consejo de Gobierno de la Junta de Extremadura 55/2007, por el que se aprobó definitivamente este proyecto fue objeto por Ecologistas en Acción-CODA de un recurso contencioso-administrativo». El Tribunal Supremo resolvió que «se escogen unos terrenos de una protección medioambiental extrema, sin conocerse si era admisible la ubicación del mismo en terrenos con menor protección o incluso sin protección alguna que existiera en la comarca que se dice querer beneficiar» (STS de 3 de julio de 2009).

81 El «límite que impone la Constitución a las leyes singulares, no sólo exige que la apreciación de la excepcionalidad no sea arbitraria, sino que las medidas adoptadas sean razonables y proporcionadas a la situación excepcional a la que se pretende dar respuesta con su aprobación, que no es otra que la especial importancia del plan para el desarrollo económico y social de la Comunidad Autónoma. El legislador no ha explicitado las razones por las que entiende que la utilización de la ley es una medida razonable y proporcionada, aún a sabiendas de que, tal y como se puso de manifiesto en el debate legislativo, la utilización de la ley eliminaba el control de la jurisdicción contencioso-administrativa». Por STC 203/2013 se resolvió la inconstitucionalidad de la Ley de las Cortes de Castilla y León 6/2007, de aprobación del Proyecto Regional Ciudad del Medio Ambiente. En el mismo sentido entre otras, STC 129/2013, que declara la inconstitu- 
En otras ocasiones las actuaciones sobre vías fluviales y nuevas vías de comunicación han evidenciado el riesgo potencial para el medio ambiente de su ejecución pese a las aparentes ventajas de desarrollo económico de dichos proyectos $^{82}$.

Pero sin duda ha sido en los proyectos de nuevos desarrollos urbanísticos donde se aprecia, en algunas ocasiones, la ausencia de justificación suficiente por las administraciones competentes del cambio de calificación del suelo con la consiguiente infracción del ordenamiento ambiental. En diversos supuestos los Tribunales han señalado la obligación de las administraciones de llevar a cabo expresamente la justificación suficiente de dicha modificación ${ }^{83}$. Algunos de estos proyectos constituyen sin duda alguna una clara manifestación de la regresión ambiental, más allá de los efectos de seguridad jurídica que conlleva para los distintos operadores jurídicos. Sucede así que la administración autonómica, a través de disposiciones reglamentarias, ha impulsado la realización de determinados proyectos de dudosa compatibilidad con la protección ambiental. En este sentido, la aprobación definitiva de un Plan Parcial de ordenación de un sector de un municipio, sin atender la exigencia de llevar a cabo la evaluación

cionalidad de la Ley de las Cortes de Castilla y León 9/2002, sobre declaración de proyectos regionales de infraestructuras de residuos de singular interés para la Comunidad.

82 El Tribunal Supremo ha concluido que cuando una actuación, como el dragado del canal de navegación del Puerto de Sevilla, comporta o puede comportar, en virtud del principio de precaución, un empeoramiento de las masas de aguas, contraviniendo lo exigido en la Directiva Marco de Aguas 2000/60 de la Unión Europea, «han de justificarse en el plan los motivos de tales modificaciones y alteraciones, ponderando, de forma específica y concreta, las circunstancias a que se refieren los apartados c) y d) del citado artículo 39.2, del Reglamento de Planificación Hidrológica con mayor energía cuando se pone en riesgo un lugar singularmente protegido desde el punto de vista medioambiental como es Doñana» (STS de 26 de febrero de 2015).

83 «El control jurisdiccional de las administraciones, (...), no puede irrumpir en el corazón de la potestad discrecional, valorando la oportunidad de la decisión y, mucho menos, sustituyendo la elección administrativa. Los tribunales de lo contencioso-administrativo han de ceñirse, pues, a verificar los hechos para comprobar si la decisión planificadora discrecional guarda coherencia con ellos, de suerte que, si aprecian una incongruencia o una discordancia de la solución elegida con la realidad que integra su presupuesto o una desviación injustificada de los criterios generales del plan, tal decisión resultará viciada por infringir el ordenamiento jurídico y, más concretamente, el principio de interdicción de la arbitrariedad, que, en lo que ahora importa, aspira a evitar que se traspasen los límites racionales de la discrecionalidad para convertirla en fuente de decisiones huérfanas de la debida justificación. Una vez comprobado que una concreta determinación del plan incurre en un desvío de esa naturaleza, procede su anulación, pero los jueces no podemos reemplazarla por otra a nuestro antojo, pues, tratándose de potestades discrecionales, siempre existen varias soluciones lícitas y razonables entre las que debe escoger la Administración, titular de esta potestad discrecional, salvo que las líneas del planeamiento conduzcan a un único desenlace, que se imponga ya por razones de coherencia» (STS de 5 de febrero de 2015). 
estratégica del mismo constituye un incumplimiento de la normativa ambiental $^{84}$. Así ocurre cuando se lleva a cabo la recalificación como urbanizable de un suelo que, con anterioridad a la aprobación del nuevo PGOU del municipio estaba calificado como suelo rústico atendiendo a sus valores agrícolas y paisajísticos ${ }^{85}$, o por parte de la administración competente no se ha acreditado «la existencia de recursos hídricos necesarios para satisfacer las nuevas demandas» de la población prevista con la reforma de la ordenación urbana ${ }^{86}$.

\section{EL ESTADO DE LA CUESTIÓN}

Hemos asistido a lo largo de casi cuarenta años a un proceso de positivación y formalización de un mandato a los poderes públicos para la protección del ambiente en sintonía con los Estados de nuestro entorno. En la mayoría de las ocasiones hay que encontrar en la mera trasposición de las normas comunitarias al ordenamiento interno el surgimiento de un derecho ambiental pero que, desde la perspectiva del artículo $45 \mathrm{CE}$, tan sólo ha permitido la plasmación de derechos de configuración legal y marcado carácter procedimental, para esgrimir ante los poderes públicos la exigencia de cumplimiento de sus obligaciones en esta materia.

Tras un breve recorrido por el intento de una construcción doctrinal del derecho al disfrute del medio ambiente como derecho subjetivo de difícil precisión, en cuanto a su contenido y límites, tan solo por aproximación se han podido identificar algunos bienes jurídicos objeto de protección, esencialmente vinculados con las condiciones que hacen posible la calidad de vida de las personas, desde una lectura que consideramos rígida de la distinción tradicional entre derechos y principios rectores, necesitada de superación. Ante este escenario tal vez resultara más oportuno llevar a cabo un cambio de perspectiva y abandonar el intento de centralidad del debate sobre la caracterización como derecho o principio del enunciado del artículo 45 CE. Por esta razón adquiere mayor relevancia en el momento actual centrar el estudio del artículo $45 \mathrm{CE}$ en torno a los deberes legales que, incorporados por el legislador, tienen un sustento constitucional indiscutible en aquél mandato. Pues consideramos que es la perspectiva del deber la que permite avanzar con mayor precisión en la determinación del

${ }^{84}$ Se incluían «variaciones de muy notable calado sobre las inicialmente previstas, afectando de lleno a todos los parámetros urbanísticos». Por lo que se concluye que se ha desatendido la obligación legal de llevar a cabo la evaluación ambiental estratégica (STS de 10 de marzo de 2015).

85 La administración que instó dicha recalificación no ha motivado ni justificado el cambio de calificación del suelo afectado (STS 14 de octubre de 2014).

86 STS de 8 de noviembre de 2016. 
objetivo perseguido por el constituyente para su incorporación a nuestra Norma Fundamental. Así, pese a su necesaria configuración legal, se aprecia la existencia de una serie de deberes que se imponen a ciudadanos y poderes públicos, así como una normativa sancionatoria de las conductas que los conculquen.

En el mismo sentido, queremos fijar la atención en los esfuerzos por extender la legitimación para lograr una «justicialidad» de la protección ambiental que ha resultado, a nuestro juicio, insuficiente. Prevalece, eso sí, a tenor de la experiencia el mandato a los poderes públicos, la acción positiva como deber de éstos de protección del ambiente que, a través de la integración en nuestro ordenamiento del derecho ambiental europeo, nutre de obligaciones y exigencias a nuestro legislador, y administraciones, dotando a nuestros órganos jurisdiccionales de instrumentos para sancionar en su caso los incumplimientos de este mandato en gran medida exigido por la normativa comunitaria y los convenios internacionales en los que el Estado español ha sido parte. Es en este ámbito donde el control judicial de la actuación de los poderes públicos adquiere un claro protagonismo.

Pero para llevar a cabo un análisis más ajustado a la realidad de la tutela ambiental en nuestro país, imprecisa también en sus contornos pero más comprensiva del alcance y contenido del deber de conservar el medio ambiente, el estudio y análisis de la jurisprudencia nos parece del mayor interés. Como brevemente se ha expuesto, ha sido la impugnación de determinadas actuaciones de los poderes públicos, como incluso de normativa ad boc, la que ha posibilitado visualizar otros cauces para hacer valer el cumplimiento de este deber por parte de los poderes públicos. Ocurre que en determinadas ocasiones no se ha ponderado suficientemente entre legítimos intereses económicos y la protección ambiental provocando actuaciones de los poderes públicos que los propios tribunales han anulado. El desarrollo del tipo penal para ilíctos ambientales también ha permitido consolidar una jurisprudencia sobre el incumplimiento de las obligaciones ambientales de los ciudadanos.

Title

The right-duty to protect the environment.

\section{Summary:}

I. Introduction. II. The right of enjoyment of the environment. III. The duty of protection of the environment. IV. The state of the matter. 


\title{
Resumen:
}

El artículo $45 \mathrm{CE}$ incluye el derecho a disfrutar el medio ambiente y, por tanto, la necesidad de proteger el ejercicio del mismo. En este precepto se combinan diversos postulados proteccionistas como la calidad de vida y la utilización racional de los recursos naturales con la consecución de objetivos de progreso y desarrollo. La ausencia de una ley general de medio ambiente que desarrollara el artículo $45 \mathrm{CE}$ ha sido suplida en gran medida por la transposición de normativa ambiental de la Unión europea. La jurisprudencia ha reconocido el carácter dinámico de este derecho pero no su consideración como derecho fundamental.

\begin{abstract}
:
Article 45 of Spanish Constitution foresees the right to enjoy the environment and, therefore, the need to protect the exercise of the environment. This precept combines several protectionist postulates such as the quality of life and the rational use of natural resources with the achievement of goals of progress and development. The absence of a general environmental law in order to develop this constitutional article has been filled, to some extent, by the transposition of environmental legislation of the European Union. Jurisprudence has recognized the dynamic nature of this right, but has denied the status of fundamental right.
\end{abstract}

Palabras clave:

Derecho al Medio Ambiente, Calidad de Vida

Key words:

Right environment. 